\title{
24. SEISMIC STRATIGRAPHY OF THE EASTERN EQUATORIAL PACIFIC OCEAN: PALEOCEANOGRAPHIC IMPLICATIONS ${ }^{1}$
}

\author{
Stephen F. Bloomer, ${ }^{2}$ Larry A. Mayer, ${ }^{2}$ and Ted C. Moore, $\mathrm{Jr}^{3}$
}

\begin{abstract}
The collection of Leg 138 well-log and shipboard physical-property data, in conjunction with high-resolution seismic profiles, provides an opportunity to understand the paleoceanographic significance of seismic reflectors and to gain insight into the paleoceanographic evolution of the eastern equatorial Pacific Ocean. A series of eight reflectors or reflector packages were traced between two transects connecting five Leg 138 sites. By generating synthetic seismograms at each of these sites and comparing these to the field records, the origin of these seismic reflectors was determined in terms of physical-property variations and other core measurements. In particular, these reflectors were usually associated with sharp variations in density, which in turn, are related to variations in carbonate content.

Intervals with moderate or poor nannofossil preservation indices were generally restricted to intervals below the reflectors traced in this study, suggesting that dissolution played little role in producing these reflectors. However, intervals with $T$. longissima mats were associated with many of the reflectors (R3-b, R4, R5-t, R5-b, R6) at the three sites (847, 849, and 850) where this diatom was encountered. This suggests that the reflectors found in this study are related to productivity events, although these events manifested themselves in a different way at the sites in which T. longissima mats were not observed.

Interpreted seismic stratigraphic sections were compiled from the reflector horizon data for the two transects. Along the western transect, the section between reflectors R3 and R8 thins abruptly north of $1^{\circ} 40^{\prime}$ to $1^{\circ} 50^{\prime} \mathrm{N}$, suggesting that this marks the northern limit of high equatorial productivity at that time (3.9-9.5 Ma), because the seafloor is reasonably constant in depth along this transect. Unfortunately, statements about sharp productivity gradients cannot be made for the eastern transect where sediment thinning corresponds to a deepening of the seafloor and thus may be related to variations in dissolution.

Finally, six reflectors were found to be associated with major paleoceanographic events; three of these reflectors correspond to those found by Mayer et al. $(1985,1986)$ in the central equatorial Pacific Ocean, suggesting that these correspond to Pacific-wide oceanographic events. One of these reflectors (R8-b) is caused by a pervasive dissolution event as is its central equatorial counterpart. The others (R3-b and R5-t), however, appear to be the result of productivity events in the eastern equatorial Pacific that are synchronous with dissolution events in the central equatorial Pacific. We suggest that while localized high productivity creates low carbonate intervals (and thus reflectors) in the eastern equatorial Pacific, steep gradients in the CCD result in enhanced dissolution and low carbonate intervals (and thus reflectors) in the deeper central equatorial Pacific.
\end{abstract}

\section{INTRODUCTION}

Seismic-reflection profiling is a widely used seafloor mapping tool. By tracing acoustic reflections, seismic profiling provides a way of mapping the regional geological structure of the ocean seafloor with a lateral resolution that cannot be achieved from information gathered in discrete boreholes. However, the reflection profile provides directly only information about arrival time and dip of reflecting interfaces. Fortunately, information about the exact nature and composition of any subsurface material can be provided by measuring cores extracted from the subsurface and by running logs in the borehole. These data can be tied to the geometrical information provided by seismic-reflection profiles by generating synthetic seismograms. This enables seismic-reflection profiling to be a powerful tool for interpreting of the geological history of a region.

Pelagic sediments are excellent indicators of the climatic and oceanographic history of a region. Generally, variations in oceanographic conditions result in changes in the physical properties of these sediments. Studies in the central and western equatorial Pacific Ocean by Mayer et al. (1985, 1986) and Mosher et al. (1993), respectively, have shown that variations in physical properties in these sediments correlate with regionally continuous seismic reflections, making seismic-reflection profiling a valuable tool for interpreting the pale-

'Pisias, N.G., Mayer, L.A., Janecek, T.R., Palmer-Julson, A., and van Andel, T.H. (Eds.), 1995. Proc. ODP Sci. Results, 138: College Station TX (Ocean Drilling Program).

${ }^{2}$ Center for Geophysical Investigation of the Shallow Subsurface, 1910 University Drive, Boise State University, Boise, ID 83725, U.S.A

${ }^{3}$ Hawaii Institute of Geophysics, University of Hawaii, 2525 Correa Rd., Honolulu, HI 96822, U.S.A. oceanography of these regions. This study attempts to correlate accurately seismic-reflection data to core data from sediments collected during Ocean Drilling Program (ODP) Leg 138 in the eastern equatorial Pacific Ocean, allowing for the interpretation of the seismic stratigraphy and for gaining insight about the paleoceanographic significance of seismic reflectors in this region.

\section{Location and Geological Setting}

The eastern equatorial Pacific Ocean has long been recognized as important in paleoceanographic studies. Because it is located in a region of divergence-driven upwelling and relatively shallow water, the sedimentary sequence is relatively expanded as compared to sites in the central equatorial Pacific where low accumulation rates and extreme carbonate dissolution results in a sedimentary record punctuated by hiatuses (Barron et al., 1985). This makes this region an excellent location for understanding the evolution of the Earth's climate. Also, the proximity of this area to the eastern boundary of the Pacific Ocean allows us to gain insight about the nature of oceanic circulation during the Miocene when open circulation between the Pacific and Atlantic Oceans was possible. To address these and other questions, the Leg 138 Scientific Party drilled 11 sites in the eastern equatorial Pacific during May through July 1991.

The drill sites form two north-south transects at approximately $95^{\circ}$ and $110^{\circ} \mathrm{W}$ (Fig. 1). The western transect (Sites 848-854) crosses the Equatorial Pacific Current (EPC) system where it is fully developed and away from the influences of eastern boundary currents and sources of fluvial sediments. This transect allows us to examine the temporal and latitudinal variability in sediment accumulation along a transect where, in surface sediments, organic carbon fluxes exhibit sharp 


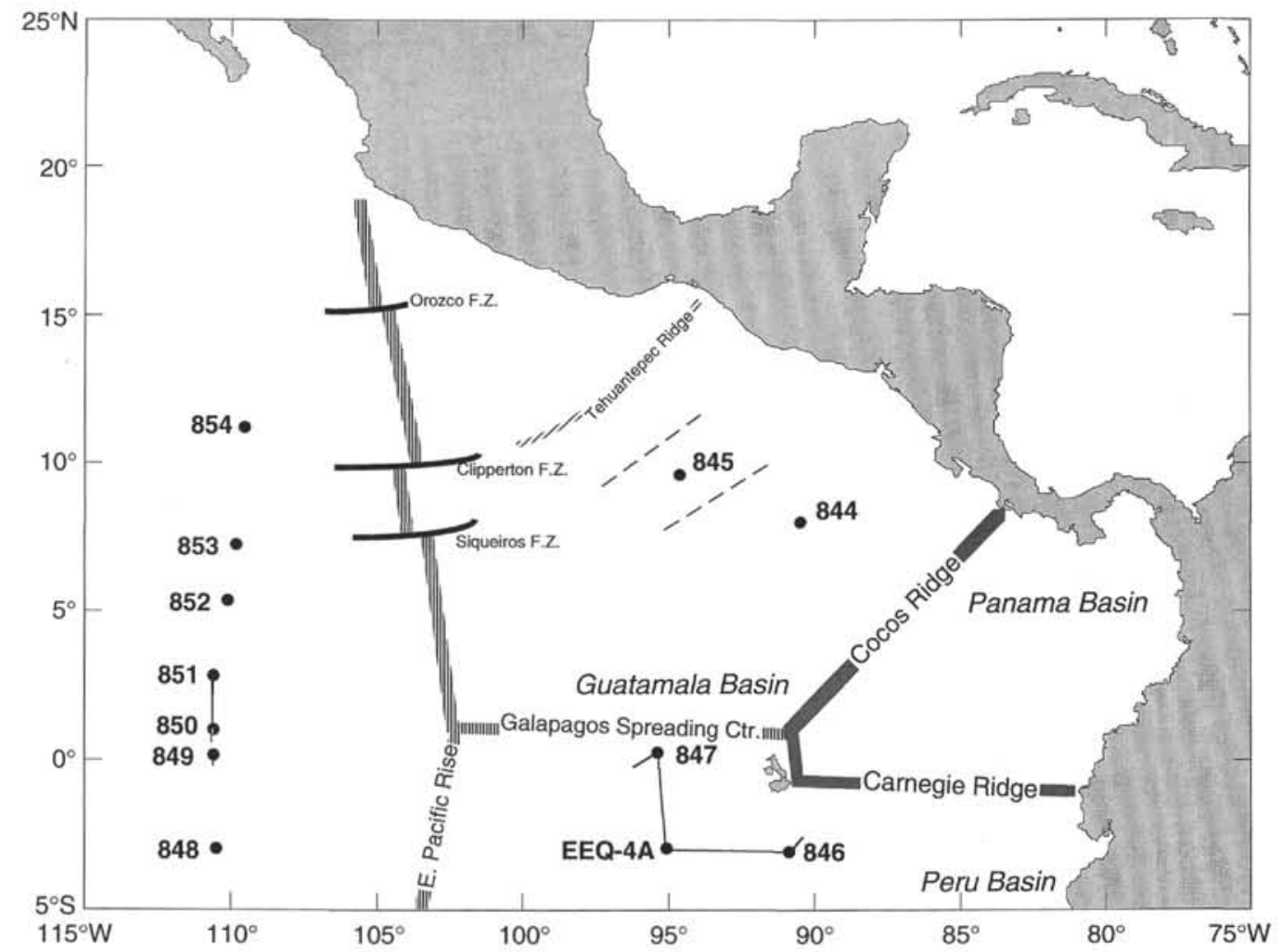

Figure 1. Location map of the eastern equatorial Pacific Ocean, illustrating the digital seismic reflection data used in this study and Leg 138 drilling site locations.

gradients near the equator (Isern, 1991) and the sites have migrated northward with time through this belt of high productivity.

The eastern transect (Sites 844-847) was designed to examine the interaction of the equatorial current system with the Peru Current (PC) and the eastern boundary of the Pacific Ocean. Therefore, the continuity of seismic sequences found in the western transect into this region of increased siliceous and terrigenous clays is of particular interest in this study.

\section{Scientific Background}

Mayer et al. (1985) showed that in the central equatorial Pacific, major regionally traceable seismic reflectors generally are related to sharp variations in density and carbonate content. Consequently, by mapping seismic reflectors, we are able to gain insight into the processes controlling carbonate sedimentation accumulation in a particular region.

Hamilton et al. (1982) stated four main factors that control pelagic carbonate deposition and accumulation. These factors are (1) the surface productivity of foraminifers and coccoliths (2) the dissolution of carbonate material as it settles through the water column and on the seafloor (3) the dilution of carbonate particles by noncarbonates, and (4) the winnowing, scour, and erosion of material on the seafloor. In the central equatorial Pacific, fluctuations in the amount of dissolution of calcium carbonate are the main cause of the major regional seismic reflectors (Mayer et al., 1985). In the western equatorial Pacific, dissolution is the major factor controlling sediment thinning with increasing depth (Mosher et al., 1993), but reflectors appear to be related to climatically driven changes in grain size due to winnowing (Mayer et al., 1993).

Both surface productivity of carbonate material and dilution by noncarbonates, especially from increased surface productivity of siliceous diatoms and radiolarians, should be important components in the seismic stratigraphy of the eastern equatorial Pacific Ocean since this region represents the high-productivity end-member of the equatorial Pacific circulation system.

\section{DATA}

\section{Seismic Reflection}

This study has two sources of digital seismic data. To facilitate the selection of Leg 138 sites, $8800 \mathrm{~km}$ of single-channel digital seismic data collected during Venture Leg 1, a site survey cruise of the Thomas Washington in August through October 1989 (Mayer, Pisias, Janecek, et al., 1992). The seismic source consisted of two synchronized 80 -in. ${ }^{3}$ Seismic Systems Inc. (SSI) water guns. The receiver consisted of a Teledyne streamer having 48 accelerator-cancelling hydrophones in a linear array. Both the source and the streamers were towed at a depth of approximately $5 \mathrm{~m}$. The digital data are of good quality and almost complete (in terms of spatial continuity between Leg 138 sites). The exception is an unfortunate gap between Sites 849 and 850 , where only unprocessed analogue records exist. These data were digitally recorded on nine-track magnetic tape at a 1-ms sampling interval for the eastern transect and a 2-ms sample interval for the western transect.

The other source of digital seismic data is from short site surveys during Leg 138 collected aboard the JOIDES Resolution. The seismic source consisted of two synchronized 80 -in. ${ }^{3}$ SSI water guns. The receiver consisted of a 100-m-long Teledyne Model 178 streamer. Both the source and the streamers were towed at a depth of approximately $10 \mathrm{~m}$. The data were digitally recorded on nine-track magnetic tape at a 1-ms sampling interval for each site survey. The quality of the JOIDES Resolution data is generally good except for the surveys of Sites 845 and 846 , where poor shielding of cables and interference of the streamer signal by the depth transducer signal produced strong noise with frequencies of $60 \mathrm{~Hz}$ and its multiples. These data are not spatially continuous between sites, however.

This study considers digital seismic data that formed two transects: one between Sites 846 and 847 and the other between Sites 849 and 
851 (Fig. 1). The sediment cover in these two transects is sufficiently thick to allow the tracing of seismic reflectors between these sites; the thinner sediment cover at Sites 848 and 852 prevent the extension of this study to those sites. The data analyzed were primarily collected aboard the Thomas Washington, except for digital data collected aboard the JOIDES Resolution near Site 849, where no digital seismic data was collected aboard the Thomas Washington.

\section{Physical Properties}

All 11 sites were drilled with multiple holes in an attempt to recover a complete sedimentary section. Discrete sediment samples were taken from the cores every 0.75 to $1.50 \mathrm{~m}$ for index-property (saturated bulk density, porosity, grain density and dry-bulk density) measurements (see Mayer, Pisias, Janecek, et al. [1992] for details of the methodology for these measurements). Longitudinal compressional $(\mathrm{P})$ wave velocities were measured on the split cores at the same depth interval as the above measurements using a digital sound velocimeter (DSV) (Mayer et al., 1987). Near continuous gamma-ray attenuation porosity evaluator (GRAPE) density was measured on the whole cores every 1 to $2 \mathrm{~cm}$.

Physical properties also were measured at the sites of interest in this study with downhole logging tools, yielding both compressional sonic velocities and density data (based on gamma-ray flux) having a sampling interval of approximately $15 \mathrm{~cm}$ and a vertical resolution of about $60 \mathrm{~cm}$ (Mayer, Pisias, Janecek, et al., 1992). These measurements are considered to be in-situ; that is, they are considered to be true values taken at actual depths. Both of these points are important. Sediment properties change as a result of changes in pressure and temperature when the sediment is brought to the surface and, hence, physical properties measured in samples must be corrected to reflect this. Also, it has been shown that the composite depth scale created by splicing together cores from different holes from the same site is almost 10\% longer than the logging depth scale (Lyle et al., 1992). The source of this discrepancy is unknown, but it indicates that care must be taken when placing laboratory measurements in a true (log) depth scale prior to creating synthetic seismograms.

\section{Other Relevant Shipboard Measurements}

Three other series of shipboard observations are important to the geological origin of seismic reflectors found here. Percentages of calcium carbonate in a given sample were measured on the core samples used for index property measurements. These measurements are important because it has been shown for central equatorial Pacific sediments that acoustic impedance contrasts responsible for seismic reflectors are associated with variations in carbonate content (Mayer et al., 1985). Observations of the state of nannofossil preservation were taken intermittently (sampling of 1-10 m) from smear slides on all Leg 138 cores (Raffi and Flores; Farrell, this volume). Using the scale described by Rio et al. (1990), samples having an index of 2 or less describe moderate or worse nannofossil preservation, indicating moderate or higher levels of carbonate dissolution. Figure 2 shows the nannofossil preservation index plotted vs. meters composite depth (mcd) for Sites 846, 847, 849, 850, and 851. Finally, intervals in which laminated $T$. longissima mats were observed also were recorded. The presence of this diatom in mats up to $50 \mathrm{~cm}$ thick indicates that processes controlling surface productivity, not just dissolution alone, are important for controlling the relative abundance of carbonate and silica in the eastern equatorial Pacific Ocean (Kemp and Baldauf, 1993).

\section{DATA PROCESSING}

\section{Seismic Correlation}

From the two transects of seismic reflection data being considered here, seven reflector horizons or packets (including seafloor and basement) were traced in each transect. These reflectors were chosen on the basis of amplitude and lateral continuity between the sites in their respective transect and because these reflectors divided the section into zones having similar acoustic character. However, because of the thinning of the sediment cover at the East Pacific Rise between the two transects, it proved impossible to trace reflectors continuously between them. Consequently, reflectors traced within the eastern transect do not necessarily correspond to reflectors traced within the western transect, although, as will be demonstrated in this paper, it is reasonable to make the inference of correspondence between reflectors traced in the two transects.

\section{Synthetic Seismograms}

Variations in the subsurface geology result in changes in acoustic impedance. Thus, the Earth can be thought of as a filter of seismic energy. If the function describing the seismic source was a delta function, the return signal recorded, in the absence of noise, would simply be a series of sharp pulses that corresponded to the arrival of different reflections, with relative amplitudes proportional to the reflection coefficients at the reflecting interfaces. The reflectivity function, the sequence of reflection coefficients with depth that is related to the change in acoustic impedance, represents the Earth's impulse response.

Generally, seismic source waveforms are not delta functions. The resulting recorded signal is the convolution of the source function and Earth's impulse response. If the source and reflectivity functions can be determined elsewhere, the convolution of these functions (synthetic seismogram) is a prescription to model seismic reflection profiles and provides a way to identify reflections with the stratigraphic changes that produce them.

Assuming a normally incident sound wave, the reflectivity function is given by

$$
r_{i}=\frac{Z_{i+1}-Z_{i}}{Z_{i+1}+Z_{i}},
$$

where $z_{i}$ is the acoustic impedance of the $t^{\text {th }}$ "layer" (Earth is assumed to be made up of a series of equally spaced layers to facilitate calculating a discrete convolution). The acoustic impedance is simply the product of the compressional (P-wave) velocity and the density of the media in which an acoustic wave travels. Thus, if density and velocity measurements can be made on cores extracted from the subsurface or by geophysical well-logging instruments in holes drilled into the subsurface, the reflectivity function can be estimated.

An accurate velocity profile is important for two reasons. First, it is vital for calculating the reflectivity function. Second, seismic profiles and source signatures are measured in terms of the traveltime of an acoustic wave from a source to the receiver, not in terms of depth, against which velocity and density are measured. However, the velocity profile permits the conversion of depth to traveltime to perform the synthetic seismogram convolution in the time domain and allows us to relate reflections to core measurements using the inverse relationship.

Density models for each site were created by merging laboratory (GRAPE) density to in-situ log density. In general, logging density and velocity measurements were available from beyond the end of the pipe (approximately $75 \mathrm{~m}$ below seafloor [mbsf]) to near the bottom of the hole. Using a software package called CORPAC (Martinson et al., 1982), GRAPE density was correlated vs. log density by shifting, squeezing, and expanding the data such that the two depth series aligned reasonably well (Harris et al., this volume). The result was a mapped depth scale between logs and core that allowed proper merging of GRAPE density to log density at approximately $75 \mathrm{mbsf}$ and in gaps where the log measurements were deemed poor.

Velocity models were created in a similar manner to that described above. To fill the gap in the upper part of the sedimentary section, laboratory velocities collected with the shipboard Digital Sound Velocimeter (DSV) were corrected to in-situ conditions for changes of sound speed as a function of temperature and pressure (Wilson, 1960). 

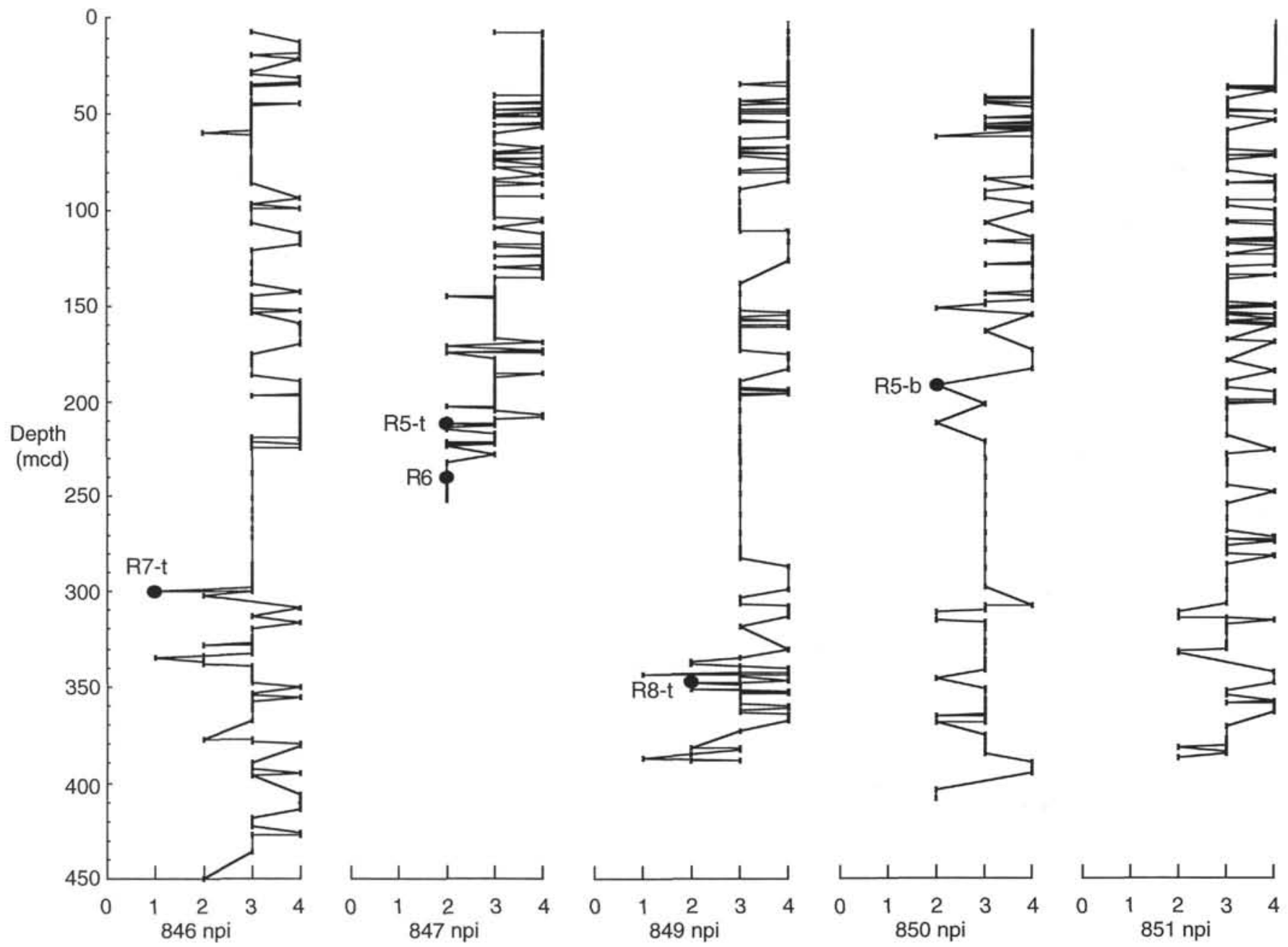

Figure 2. Plot of nannofossil preservation indexes (npi) vs. meters composite depth (mcd) for Sites $846,847,849,850$, and 851 . The values $0-4$ for the npi represent the following states of preservation: no nannofossils preserved (0), extreme dissolution and/or overgrowth (1), moderate dissolution and/or overgrowth (2), slight dissolution and/or overgrowth (3), and little or no dissolution and/or overgrowth (4). The five labeled "events" represent the four reflectors found in this study that correspond to a moderate or higher level of dissolution based on the npi.

Corrections for porosity rebound were not used for two reasons. First, MacKillop et al. (this volume) performed consolidation tests to determine porosity rebound only on eastern transect sites and determined that the rebound is a function of both depth and lithology. This means that no simple correction could be extended to the western transect sites. Second, the difference between velocities corrected and uncorrected for porosity rebound at all the sites in this study is small. Figure 3 shows the difference between these velocities for Site 847, where the in-situ corrected velocity almost precisely joins the log velocity curve at $75 \mathrm{~m}$. The difference between porosity rebound corrected and uncorrected velocities in the interval 0 to $75 \mathrm{~m}$ averages 8 $\mathrm{m} / \mathrm{s}$, with a maximum discrepancy of $11 \mathrm{~m} / \mathrm{s}$.

The seismic source function used for the generation of synthetic seismograms in marine studies is often the far-field source signature, measured with a calibrated hydrophone. For this study, the far-field source signature of the Thomas Washington 80 -in. ${ }^{3}$ water-gun measured during the Leg 130 site-survey cruise was used (Shipboard Scientific Party, 1991).

Synthetic seismograms were generated for each site using these density, velocity, and source signature models. Using the velocity models, depths were converted to traveltime, and the velocity and density models were re-sampled at a $1 \mathrm{~ms}$ rate (approximately $70 \mathrm{~cm}$ ) using linear interpolation. Acoustic impedance and reflection coefficients then were calculated, and by using a 1-ms-sampled source function, synthetic seismograms were generated. Density and velocity values typical of basalt $\left(2.5 \mathrm{~g} / \mathrm{cm}^{3}\right.$ and $3000 \mathrm{~m} / \mathrm{s}$, respectively) were added at the basement depth to generate a basement reflector in the synthetic seismogram to aid correlation between the synthetic seismogram and the seismic section. The modelling procedure used to generate the synthetic seismograms is the same as that used by Mayer et al. (1985) and assumes plane waves, no multiples, and no signal attenuation. The final synthetic seismograms were filtered from 70 to $250 \mathrm{~Hz}$, the same filter parameters as the seismic data collected during the survey cruises of the Thomas Washington and JOIDES Resolution and approximately the effective bandwidth of the source.

\section{RESULTS \\ Correlation of Core-Reflection Data}

Figures 4 through 8 show the comparison of the synthetic seismograms generated to the field records at Sites $846,847,849,850$, and 851 , respectively. In general, the match between the synthetic and field records was within $5 \mathrm{~ms}$ (approximately $4 \mathrm{~m}$ ). Discrepancies may result from (1) errors in the velocity profile used when converting reflectors to depth, (2) the uncertainty of the location of the drill site with respect to the seismic profile, and (3) the source signature differing from the representative signature during the collection of the seismic profile, but the good match between the synthetic and field 


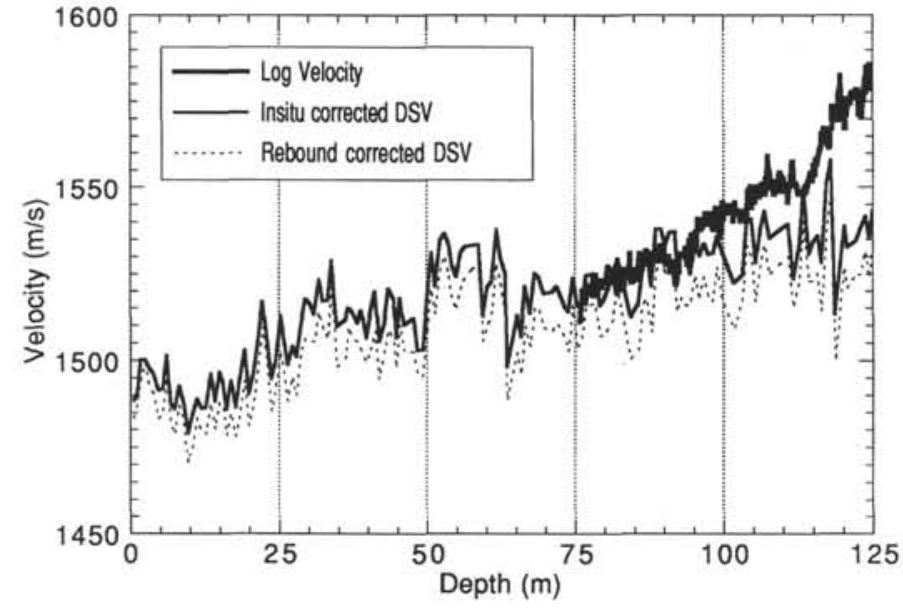

Figure 3. Plot of Site 847 log velocity, laboratory velocity corrected for in-situ temperature and pressure, and laboratory velocity corrected for in-situ temperature and pressure, as well as porosity rebound vs. depth below seafloor. This demonstrates that in-situ corrections alone are adequate to properly splice laboratory to $\log$ velocity.

records verifies the velocity model used at each site and allows us to determine the age and the origin of the reflectors in terms of physical-property variations and other paleoceanographic indicators.

At each site, the two-way traveltime of each reflector traced between the sites was measured from the field record to determine the age and origin of these reflectors. By measuring traveltime from the field record, and not the synthetic seismogram, the potential stratigraphic miscorrelation of a reflector can be maximized, but assures that the correct reflector is used. By using the velocity model for each site, traveltime to each reflector was converted to log depth. Typically, within $2 \mathrm{~m}$ of this depth an associated sharp change in acoustic impedance occurs. Discrepancies between the predicted depth from the reflector and the sharp change in acoustic impedance are due again to errors in the velocity model and site location, and from reflectors in deep-sea carbonate sequences that resulted from the constructive interference from numerous interfaces, not from a single geological horizon, as demonstrated by Mayer (1979).

Figures 9 through 13 show these reflectors plotted vs. velocity, density, acoustic impedance, and carbonate content for sites of the eastern and western transects used here. As in the central equatorial Pacific, impedance generally fluctuates with density, as can be seen in these plots. For the deeper (older) reflectors (R5-R8), variations in acoustic impedance are related to simultaneous variations in density and velocity, although the density variations still dominate. The reason for this simultaneous variation in density and velocity in the lower part of the section is simple. Downhole, porosity, which is inversely related to wet-bulk density, decreases because of compaction. As the porosity decreases and interparticle contact occurs, the rigidity of the sediment, and consequently the velocity, increases. These plots also demonstrate that the acoustic reflectors are in turn related to variations in carbonate content, which suggests that the processes affecting the accumulation of carbonate content are responsible for these reflectors.

The depth of the sharp change in acoustic impedance associated with the acoustic reflectors then was converted to core depth (in mcd) using the log vs. core depth relationships established by Harris et al. (this volume) and finally to age using the age vs. depth models for this leg established by Shackleton (this volume). Table 1 summarizes the determination of reflector age from two-way traveltime. Figure 14 summarizes the reflector age results of this study. Note that the age determined for each reflector corresponds well between sites. This is important as it allows us to infer the correspondence of reflectors between transects and sites where reflectors could not be traced directly.

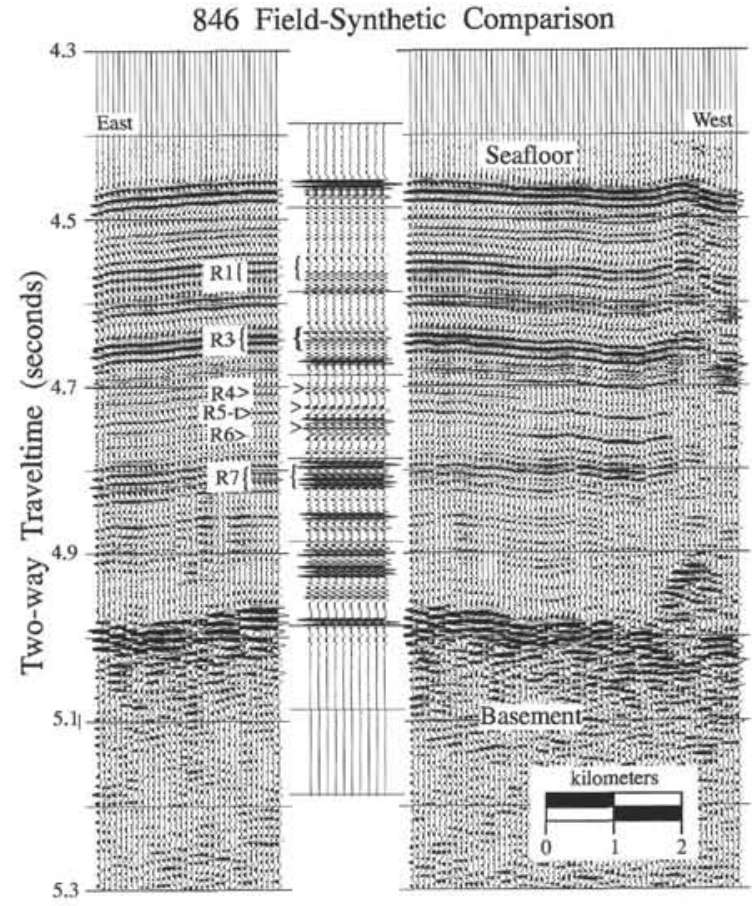

Figure 4. Comparison of the synthetic seismogram with the seismic reflection profile collected over ODP Site 846 . The seismic reflection profile was collected during the Venture Leg 1 site survey cruise of the Thomas Washington. The site is located in a water depth of $3296 \mathrm{~m}$.

By plotting reflector positions on the acoustic impedance curves for various sites, the case for the correspondence of reflectors can be further strengthened. Figure 15 shows the acoustic impedance and the reflector positions for the western transect sites. One notes that reflectors R1 through R5 all correspond to acoustic impedance and, hence, carbonate minima. R6 and R8 correspond, or are proximal to, an extreme carbonate minima.

Figure 16 shows the acoustic impedance and the reflector positions for the eastern transect sites and for Site 850. This allows one to compare between transects. Good correspondence exists between extreme in the acoustic impedance profiles at R1-b, R3-t, R3-b, and R6, and small discrepancies occur at R5-t for both the eastern and western transect sites, indicating that all these reflectors are most likely representative of regional events. There may be some relationship between R7 in the eastern transect and R8 in the western transect since there is a similarity in age, but the variations in acoustic impedance at Site 846 are not as large as those at the western transect sites. The tracing of R7 through to Site 847 , which would aid in clarifying the relationship between R7 and R8, was inhibited by the formation of chert at Site 847 and the uncertainty of the relationship, if any, between R7 and the chert reflectors.

Beside the acoustic impedance profiles in Figures 15 and 16 are plotted the intervals where laminated mats of $T$. longissima were observed in the cores (A.E.S. Kemp, pers. comm., 1993). Mats of this diatom are found only in cores from Site 847,849 , and 850 , resulting in extreme minima in the acoustic impedance curves at these sites. Reflector R3-b at all three of these sites corresponds to intervals where T. longissima mats were observed; thus, this reflector is certainly related to silica productivity at these sites. R5-t and R6 correspond as well to intervals where $T$. longissima mats were observed at Sites 847, 849 , and 850 . However, mats of this diatom are not present at Sites 846 and 851 , although this reflector is continuous in the two transects. T. longissima is, however, present in burrow fills at Site 851 (Kemp, this volume). 
847 Field-Synthetic Comparison

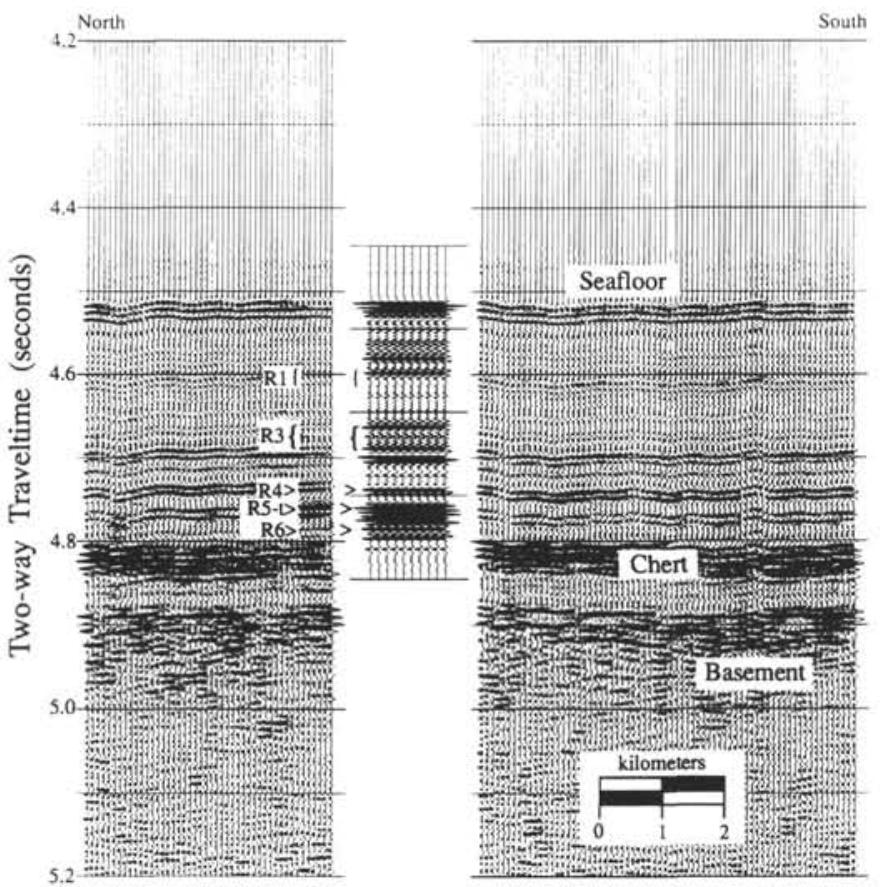

Figure 5. Comparison of the synthetic seismogram with the seismic reflection profile collected over ODP Site 847. The seismic reflection profile was collected during the Venture Leg 1 site survey cruise of the Thomas Washington. The site is located in a water depth of $3334 \mathrm{~m}$. R6 was not traced from Sites 846 to 847 , but may be the chert interval identified in this figure.

849 Field-Synthetic Comparison

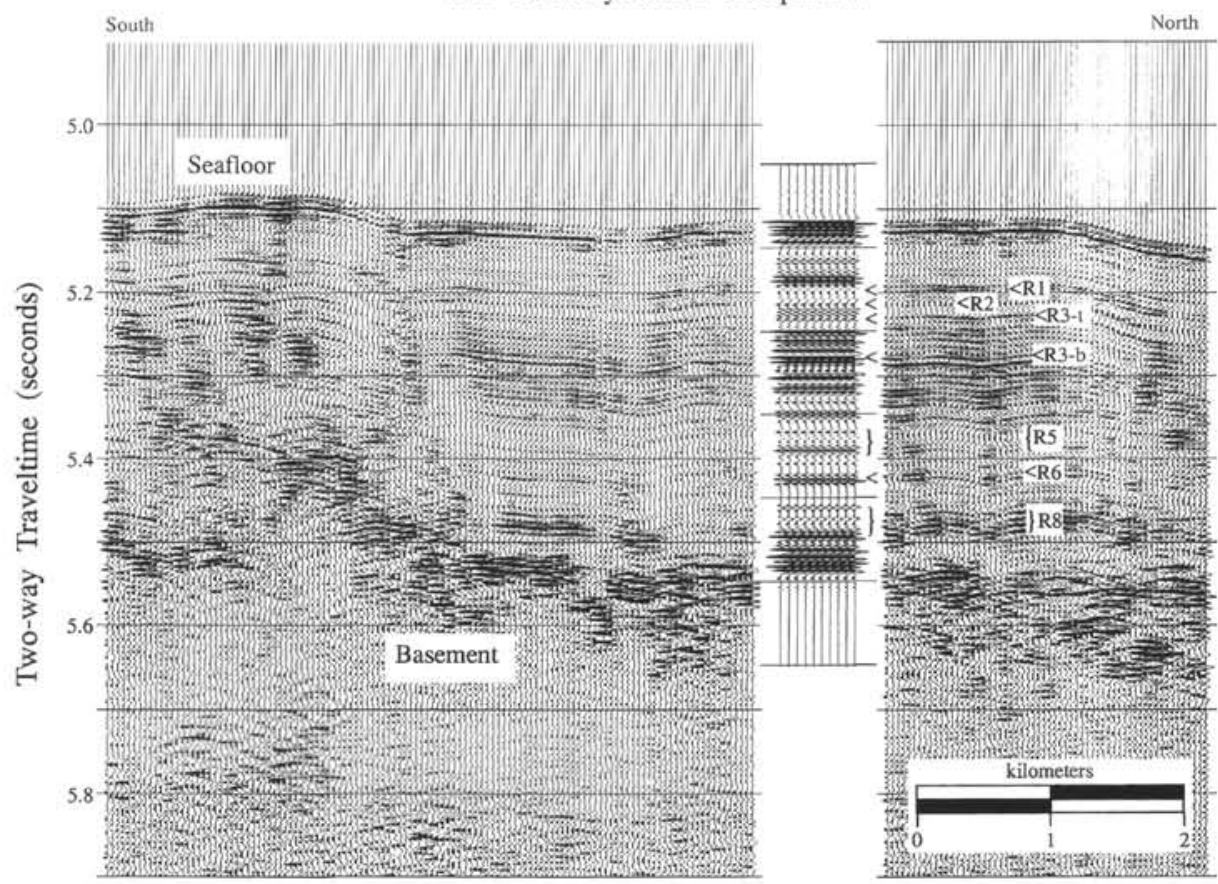

Figure 6. Comparison of the synthetic seismogram with the seismic reflection profile collected over ODP Site 849. The seismic reflection profile was collected during the Leg 138 site survey cruise of the JOIDES Resolution. The site is located in a water depth of $3837 \mathrm{~m}$. 


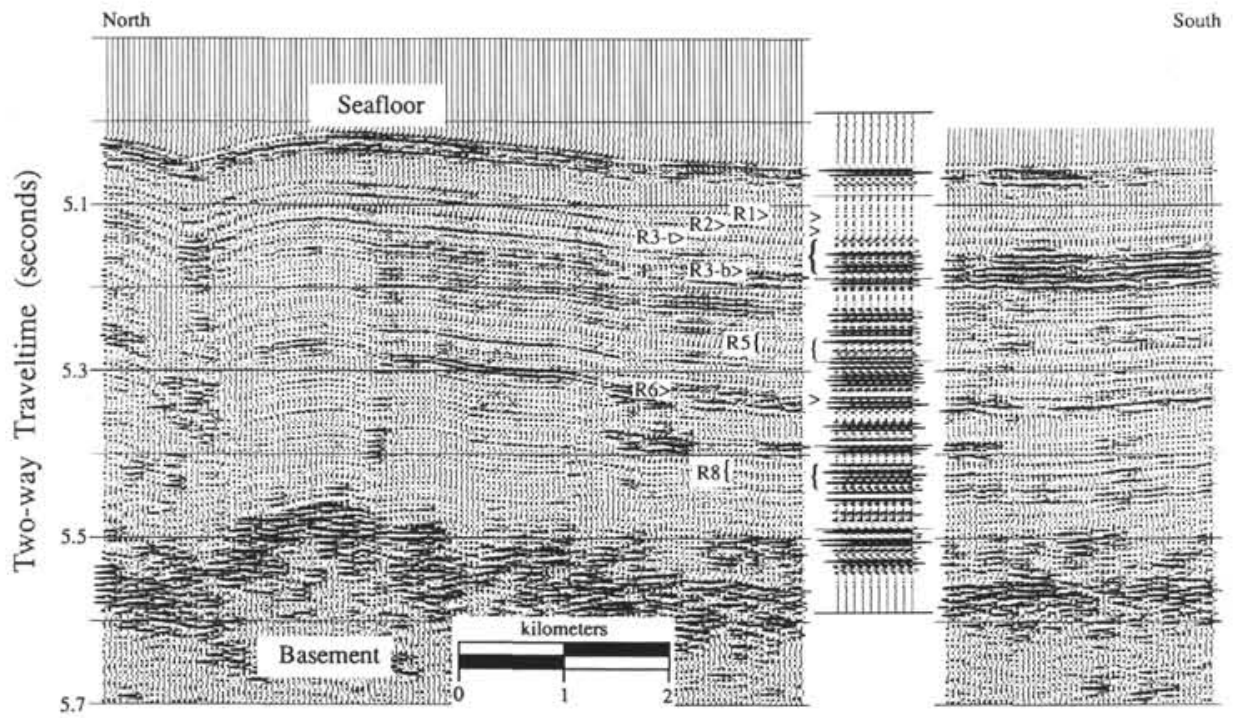

Figure 7. Comparison of the synthetic seismogram with the seismic reflection profile collected over ODP Site 850 . The seismic reflection profile was collected during the Leg 138 site survey cruise of the JOIDES Resolution. The site is located in a water depth of $3786 \mathrm{~m}$.

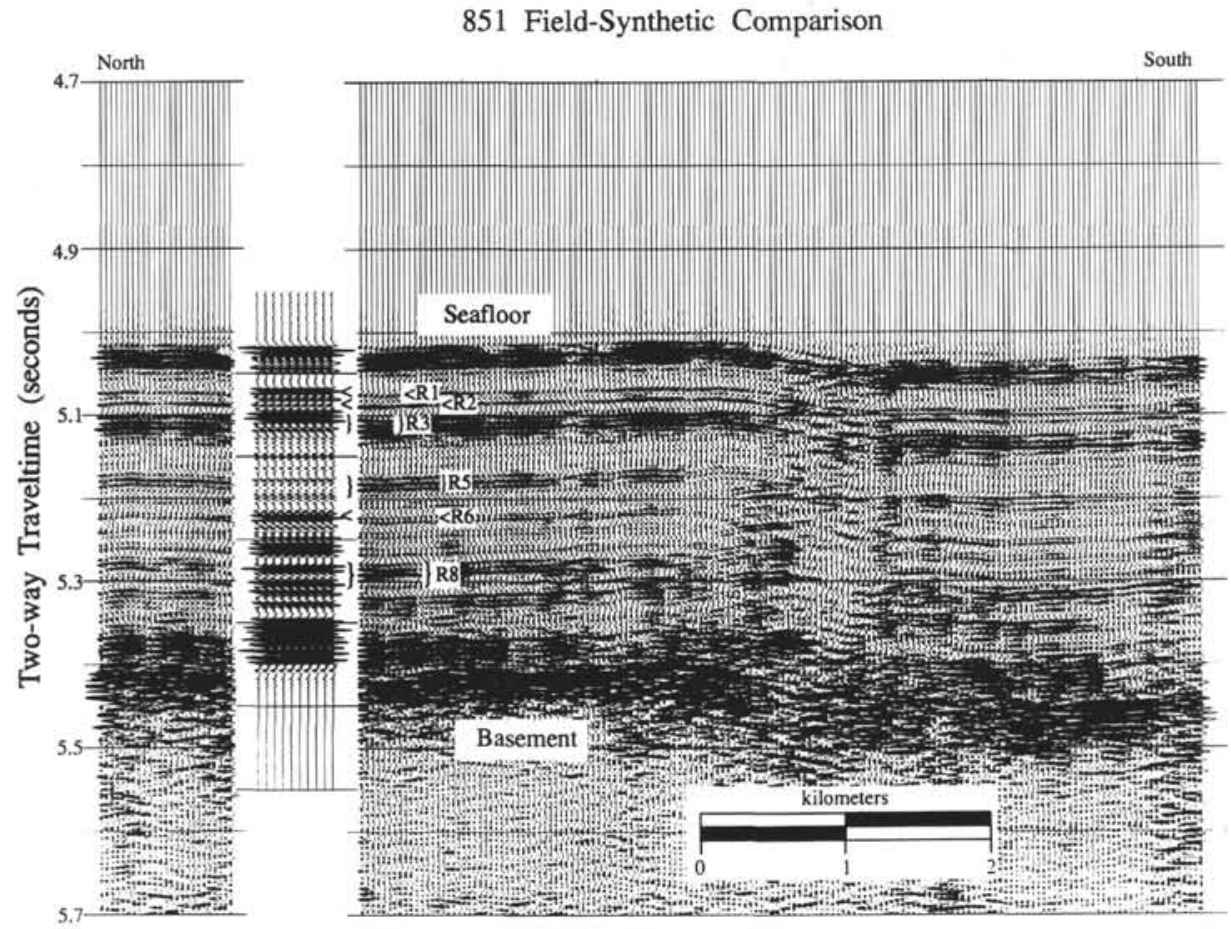

Figure 8. Comparison of the synthetic seismogram with the seismic reflection profile collected over ODP Site 851. The seismic reflection profile was collected during the Leg 138 site survey cruise of the JOIDES Resolution. The site is located in a water depth of $3760 \mathrm{~m}$.

Comparing the depths of the reflectors in Table 1 with the depths of moderate or higher dissolution (nannofossil preservation indexes of 2 or less) in Figure 2 shows that few reflectors can be related to intervals having poor nannofossil preservation. At the Leg 138 sites, moderate to poor nannofossil preservation is usually associated with sediments $9 \mathrm{Ma}$ or older, which is older than the ages associated with the majority of the reflectors traced in this study. The one exception to this is R8-b, which corresponds to a moderate level of dissolution at 849 (Fig. 2) and is the same age as carbonate-free radiolarian clay horizons at the off-equator sites 848 and 852 (Kemp, this volume). However, in general, this lack of correlation between nannofossil preservation and seismic reflectors indicates that, in contrast to the central equatorial Pacific, little evidence can be found to indicate that dissolution is the main process creating the seismic reflectors in this study. 


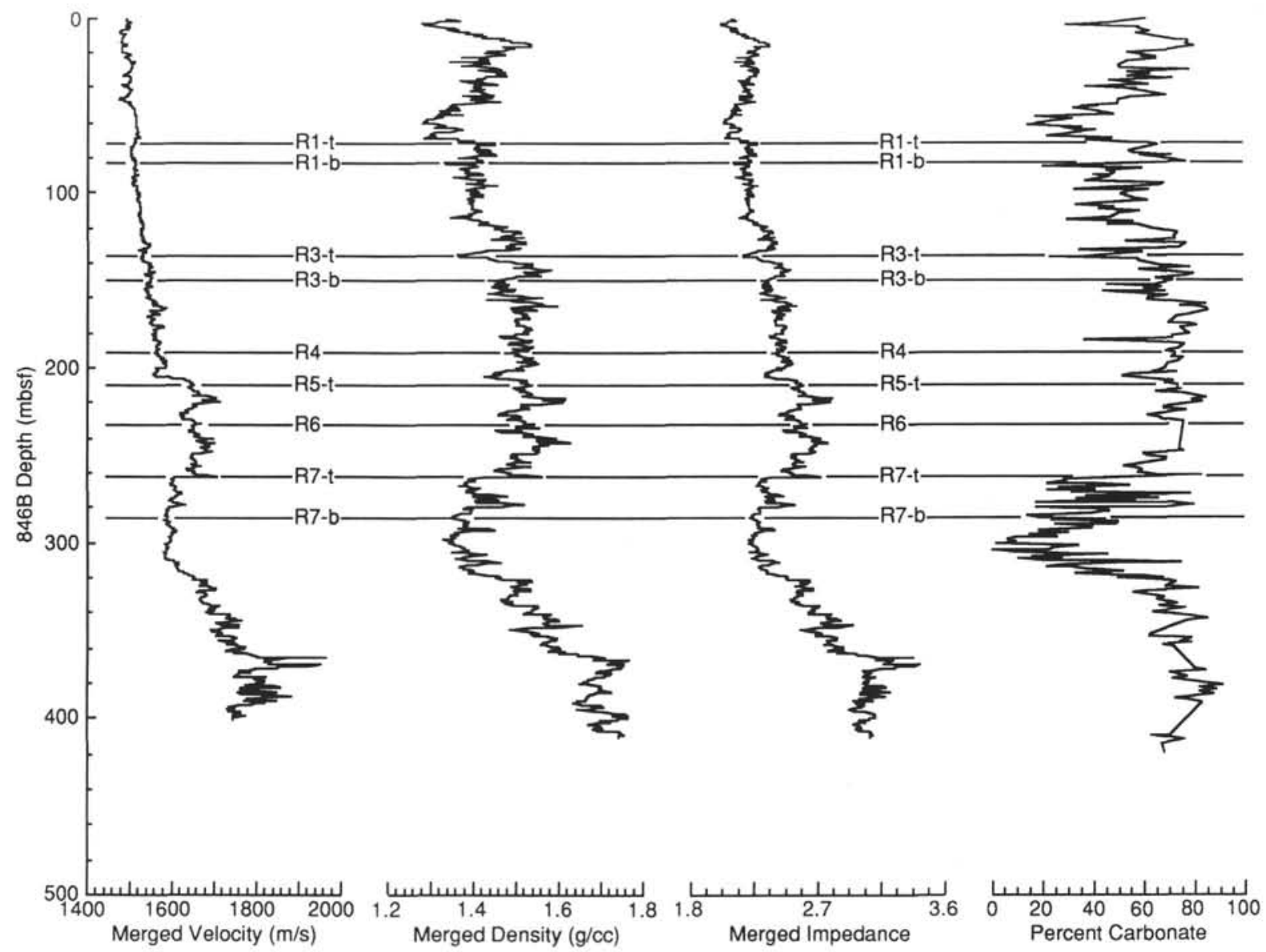

Figure 9. Plot of velocity, density, acoustic impedance, and carbonate content from ODP Site 846, with the depths of the reflectors traced in Figure 3 shown for comparison. Note that the reflectors correspond to sharp changes in carbonate content as well as physical properties.

\section{Seismic Correlation}

The tracing of seismic reflectors allows us to examine variations in thickness between reflectors and, hence, to examine regional variations in gross sedimentation rate with a lateral resolution much greater than can be achieved with only discrete borehole information. Figure 17 shows the interpreted seismic section for the western transect of sites. Notably, the section between reflectors R3 and R8, with ages of approximately 4 to $9.5 \mathrm{Ma}$, abruptly thins $(0.25-0.20 \mathrm{~s}, 194-\mathrm{m})$ north of $1^{\circ} 40^{\prime}$ to $1^{\circ} 50$ N, although, if anything the basement is deeper south of $1^{\circ} 40^{\prime} \mathrm{N}$. This transect of sites has a reasonably constant water depth (3750-3900 mbsl), and no correlation between seafloor depth and the thickness is seen between R3 and R8 (Fig. 18), suggesting that dissolution resulting from increased seafloor depth is not an important factor in the thinning of this section. However, reflectors R3 and R8 correspond to extreme density minima and the presence of $T$. longissima mats in Site 850 cores, suggesting that this marks the time average northern limit of high equatorial productivity at that time. This would explain thicker sediments over deeper basement as demonstrated in Figure 17.

Figure 19 shows the interpreted seismic section for the eastern transect of sites. Between Site 847 and EEQ-4A (an undrilled site at $3^{\circ} 01^{\prime} \mathrm{S}, 95^{\circ} 20^{\prime} \mathrm{W}, 3535 \mathrm{mbsl}$ ), the sedimentary section between reflectors R1 and R5 (2-6.5 Ma) thins from about 0.20 to $0.17 \mathrm{~s} \mathrm{(153-}$ $129 \mathrm{~m}$ ) abruptly at about $1^{\circ} 20^{\prime}$ to $1^{\circ} 30^{\prime} \mathrm{S}$. As shown in Figure 20, a plot of the sediment thickness between R1 and R5 vs. seafloor depth forms two clusters reflecting this abrupt change. Two possible mechanisms may explain this thinning. This change in sediment thickness may be the result of increasing dissolution with depth, but one might perhaps expect a simple relationship between seafloor depth and sedi- ment thickness, which clearly does not exist here. The other possibility is that this abrupt change represents the limit of the equatorial productivity belt at that time.

Between EEQ-4A and Site 846, the sedimentary section from reflectors R1 and R5 is reasonably constant in thickness. However, the section above RI generally thickens to the east and is greatly expanded at Site 846 . Site 846 is located on the top of a small high, so again the thicker sedimentary section representing the last $2 \mathrm{~m} . \mathrm{y}$. at Site 846 may be due to decreasing dissolution with shallower water depth. However, Figure 21 demonstrates again that there is no simple relationship between water depth and depth of R1. It is more likely we are seeing the influence of the Peru Current over the last 2 m.y.

\section{PALEOCEANOGRAPHIC SIGNIFICANCE OF REFLECTORS}

Having established that the major, regionally traceable reflectors of the eastern equatorial Pacific are caused by significant changes in carbonate content, we explore the processes that might be responsible for these carbonate shifts as well as the relationship of eastern equatorial Pacific reflectors to those mapped in the central equatorial Pacific.

In a study of the paleoceanographic significance of seismic reflectors in the central equatorial Pacific, Mayer et al. (1986) demonstrated that regionally traceable reflectors were synchronous and were the result of dissolution events that could be linked to regional, if not global changes in deep ocean chemistry in response to major climatic and tectonic events. Examining the reflectors of the eastern equatorial Pacific in the same light reveals that they differ from the eastern equatorial Pacific reflectors in terms of the local processes responsible for their 


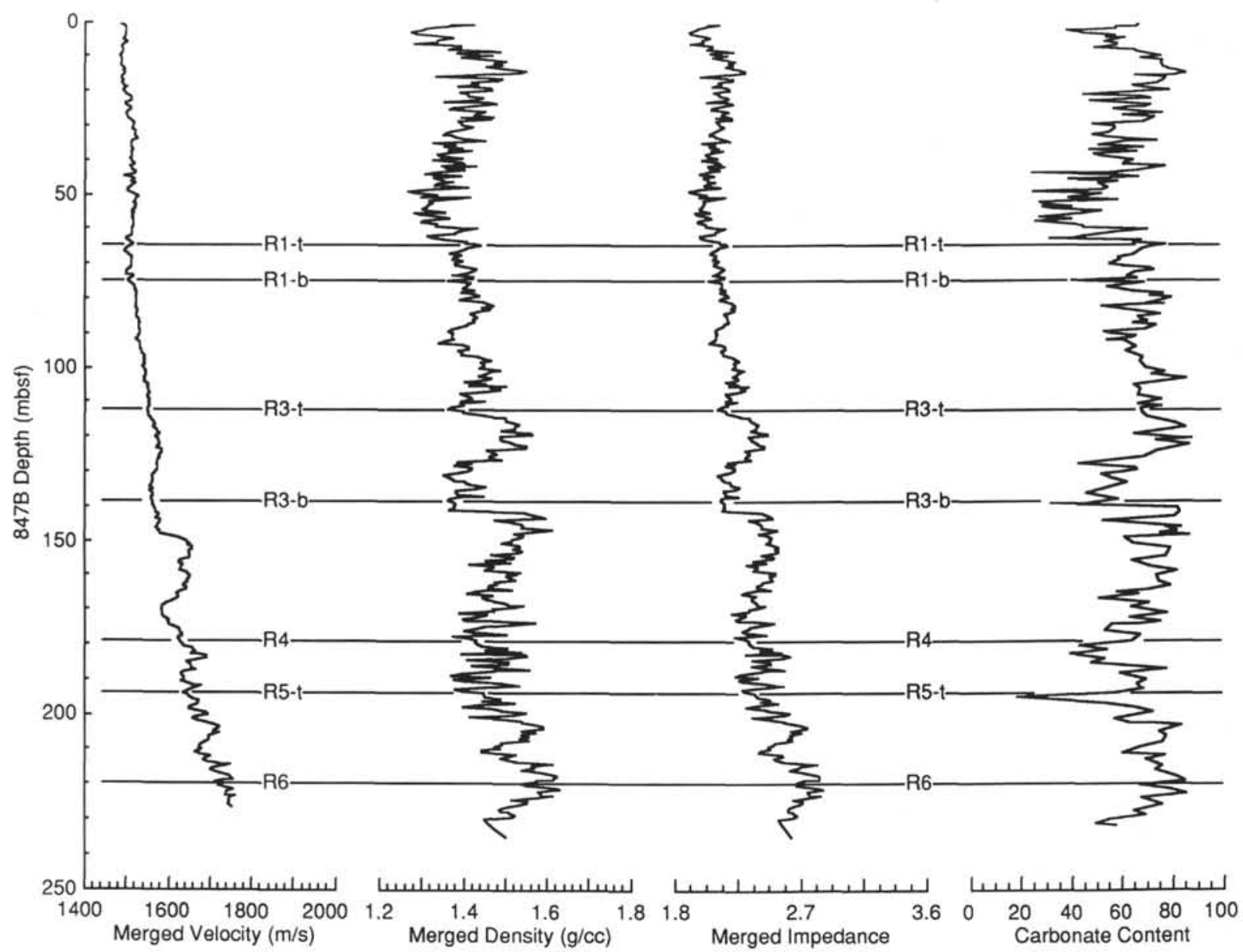

Figure 10. Plot of velocity, density, acoustic impedance, and carbonate content from ODP Site 847, with the depths of the reflectors traced in Figure 4 shown for comparison. Note that the reflectors correspond to sharp changes in carbonate content as well as physical properties.

impedance contrasts, but they may well fit into a coherent regional framework of sedimentological response to basin-wide (or global) events.

By relating the reflectors found in this study to major carbonate events described in other studies (Prell, 1985; Dunn and Moore, 1981; Vincent, 1981; Keigwin, 1979) that correlate with significant oceanographic events and then attempting to relate the reflectors in this study to those events by matching biostratigraphic zones and carbonate events, some general correlations can be made. The detailed biostratigraphic analysis required to establish precise relationships is, however, beyond the scope of this study.

A summary of the biostratigraphic zones for the major reflectors found in this study and from Leg 85 (Mayer et al., 1986) is given in Table 2, using the radiolarian, diatom, and nannofossil zonation schemes (Moore; Baldauf; Raffi and Flores, respectively, this volume) developed for this leg. A summary of oceanographic events associated with each of the reflectors listed in Table 2 then is presented in Table 3. Acknowledging the difficulty in establishing synchroneity amongst events established with different stratigraphic bases, an examination of the eastern equatorial Pacific reflectors reveals that three of the reflectors (R3-b, R5-t, R8-b) can be correlated (on the basis of biostratigraphic zonation) to those identified in the central equatorial Pacific. Further tracing of central equatorial Pacific reflectors may provide links to the other reflectors found in this study.

Reflector R8-b (early late Miocene) corresponds to the Leg 85 purple reflector (IM-P) and, as in the central equatorial Pacific, appears to be caused by a pervasive dissolution event. A detailed look at the purple "event" in the central equatorial Pacific revealed that it is actually represented by a sequence of events: an isotopic excursion from relatively heavy oxygen isotope values to relatively light ones followed by an extreme carbonate dissolution event and then a rapid return to relatively high carbonate values (Berger and Mayer, 1987).

In contrast to the reflectors of the central equatorial Pacific (each of which appear to be linked to a dissolution event), the reflectors of the eastern equatorial Pacific appear to be linked to the presence of $T$. longissima mats (R3-b, R5-t, R5-b, R6). Most intriguingly, several of these reflectors (R3-b and R5- $t$ ) appear to be synchronous with those of the central equatorial Pacific (P-Green and IM-Magenta, respectively).

The dominance of the sediment by the fiberlike $T$. longissima (with a solid grain density of $\sim 2.1 \mathrm{~g} / \mathrm{cm}^{3}$ as opposed to $2.6 \mathrm{~g} / \mathrm{cm}^{3}$ for carbonate) results in a greatly reduced carbonate content and saturated bulk density. This reduced density produces in an impedance contrast that is an excellent candidate for generating a major reflector. Unlike the reflectors of the central equatorial Pacific, which appear to be the result of the removal of carbonate by dissolution, the correlative reflectors of the eastern equatorial Pacific appear to be related to the reduction of carbonate content due to dilution by massive productivity events (Kemp and Baldauf, 1993).

One possible explanation for this apparent contradiction is the response of the $\mathrm{CCD}$ to the regionally restricted but intense productivity events that may be responsible for the $T$. longissima mats. An increased flux of organic matter that is localized in the eastern equatorial Pacific would result in the massive outpouring of opal beneath the locus of mat production (probably associated with the position of a front; see Kemp, Baldauf, and Pierce, this volume) and thus extremely low carbonate contents due to dilution by silica. This is clearly a mechanism to make a reflector. Outside the locus of enhanced opal deposition, steep gradients in the CCD combined with a reduced flux of carbonate would lead to enhanced dissolution of carbonate-also 
Table 1. Summary of traveltimes, depths, and ages assigned to the seismic reflectors traced at $\mathrm{Leg} 138$ Sites $846,847,849,850$, and 851 .

\begin{tabular}{|c|c|c|c|c|c|c|}
\hline Site & Reflector & $\begin{array}{l}\text { Traveltime } \\
\text { (ms) }\end{array}$ & $\begin{array}{c}\text { Seismic } \\
\text { depth } \\
\text { (m) }\end{array}$ & $\begin{array}{l}\text { Event } \\
\text { depth } \\
\text { (m) }\end{array}$ & $\begin{array}{l}\text { Event } \\
\text { depth } \\
\text { (med) }\end{array}$ & $\begin{array}{l}\text { Age } \\
(\mathrm{Mi})\end{array}$ \\
\hline \multirow[t]{9}{*}{846} & RI-t & $95-100$ & $71.2-74.9$ & 72.3 & 83.7 & 2.21 \\
\hline & RI-b & $112-117$ & $84.0-87.8$ & 83.3 & 95.4 & 2.49 \\
\hline & R3-1 & $172-177$ & $129.6-133.4$ & 135.3 & 154.2 & 3.96 \\
\hline & R3-b & $200-204$ & $151.2-154.2$ & 152.0 & 174.1 & 4.54 \\
\hline & R4 & $250-255$ & $190.0-193.9$ & 191.5 & 219.5 & 5.58 \\
\hline & RS-t & $271-275$ & $206.5-209.8$ & 210.4 & 242.3 & 5.93 \\
\hline & R6 & $302-306$ & $232.1-235.5$ & 232.4 & 269.5 & 6.61 \\
\hline & R7-t & $336-341$ & $260.4-264.6$ & 261.9 & 297.8 & 7.52 \\
\hline & R7-b & $363-367$ & $282.2-285.5$ & 286.0 & 322.2 & 8.97 \\
\hline \multirow[t]{7}{*}{847} & $R I-t$ & $86-90$ & $64.8-67.8$ & 65.1 & 72.7 & 2.19 \\
\hline & RI-b & $105-110$ & 1468 & 80.6 & & 2.74 \\
\hline & R3-t & $147-154$ & $111.3-116.8$ & 112.1 & 125.7 & 3.96 \\
\hline & R3-b & $180-185$ & $137.1-141.1$ & 138.5 & 155.4 & 4.70 \\
\hline & R4 & $232-235$ & $179.0-181.4$ & 178.1 & 197.6 & 5.66 \\
\hline & R5-t & $250-253$ & $193.9-196.4$ & 193.1 & 212.7 & 6.03 \\
\hline & R6 & $277-282$ & $216.6-220.9$ & 220.1 & 239.4 & 6.48 \\
\hline \multirow[t]{9}{*}{849} & RI-b & $85-88$ & $64.8-67.0$ & 64.0 & 73.0 & 2.59 \\
\hline & R2 & $100-108$ & $76.2-82.2$ & 76.0 & 87.3 & 3.15 \\
\hline & R3-1 & $118-122$ & $89.3-92.3$ & 94.5 & 109.3 & 3.94 \\
\hline & R3-b & $161-165$ & $122.6-125.7$ & 121.5 & 141.6 & 4.73 \\
\hline & R5-t & $255-260$ & $196.7-200.9$ & 195.5 & 227.9 & 6.08 \\
\hline & R5-b & $275-279$ & $213.4-216.7$ & 212.0 & 245.4 & 6.38 \\
\hline & R6 & $307-316$ & $239.6-247.4$ & 236.5 & 270.9 & 6.62 \\
\hline & R8-t & $354-359$ & $280.5-285.0$ & 283.0 & 321.5 & 8.30 \\
\hline & R8-b & $376-381$ & $299.9-304.0$ & 306.5 & 347.7 & 9.60 \\
\hline \multirow[t]{9}{*}{850} & RI-b & 63-68 & $47.5-51.3$ & & 53.8 & 2.64 \\
\hline & R2 & $78-81$ & $58.9-61.1$ & 60.0 & 65.3 & 3.15 \\
\hline & R3-t & $91-97$ & $68.8-73.8$ & 74.5 & 82.7 & 3.94 \\
\hline & R3-b & $132-135$ & $99.2-102.4$ & 99.0 & 107.4 & 4.75 \\
\hline & R5-1 & $214-217$ & $164.3-166.7$ & 166.0 & 174.3 & 6.04 \\
\hline & R5-b & $230-235$ & $177.5-181.5$ & 180.0 & 188.3 & 6.26 \\
\hline & R6 & $267-272$ & $207.1-211.1$ & 211.5 & 219.4 & 6.64 \\
\hline & R8-t & $361-365$ & $285.7-289.0$ & 286.5 & 293.6 & 8.60 \\
\hline & R8-b & $390-394$ & $309.9-3|3|$. & 313.5 & 321.6 & 9.52 \\
\hline \multirow[t]{9}{*}{851} & RI-b & $58-62$ & $43.9-46.9$ & 44.0 & 49.8 & 2.66 \\
\hline & & & $53.0-56.8$ & & 58.3 & 3.08 \\
\hline & R3-t & $85-90$ & $64.4-68.1$ & 64.0 & 72.5 & 3.88 \\
\hline & R3-b & $100-105$ & $75.7-79.5$ & 75.0 & 84.9 & 4.54 \\
\hline & R5-t & $159-163$ & $121.3-124.5$ & 122.5 & 139.1 & 6.10 \\
\hline & R5-b & $172-175$ & $131.8-134.0$ & 134.0 & 151.7 & 6.32 \\
\hline & R6 & $202-210$ & $155.5-161.8$ & 153.5 & 177.9 & 6.65 \\
\hline & R8-t & $260-265$ & $202.5-206.7$ & 207.0 & 248.3 & 8.63 \\
\hline & R8-b & 283-289 & $221.4-226.3$ & 229.5 & 278.3 & 9.58 \\
\hline
\end{tabular}

Table 3. Summary of reflectors found in this study, their approximate ages, associated paleoceanographic indicators, and associated paleoceanographic events.

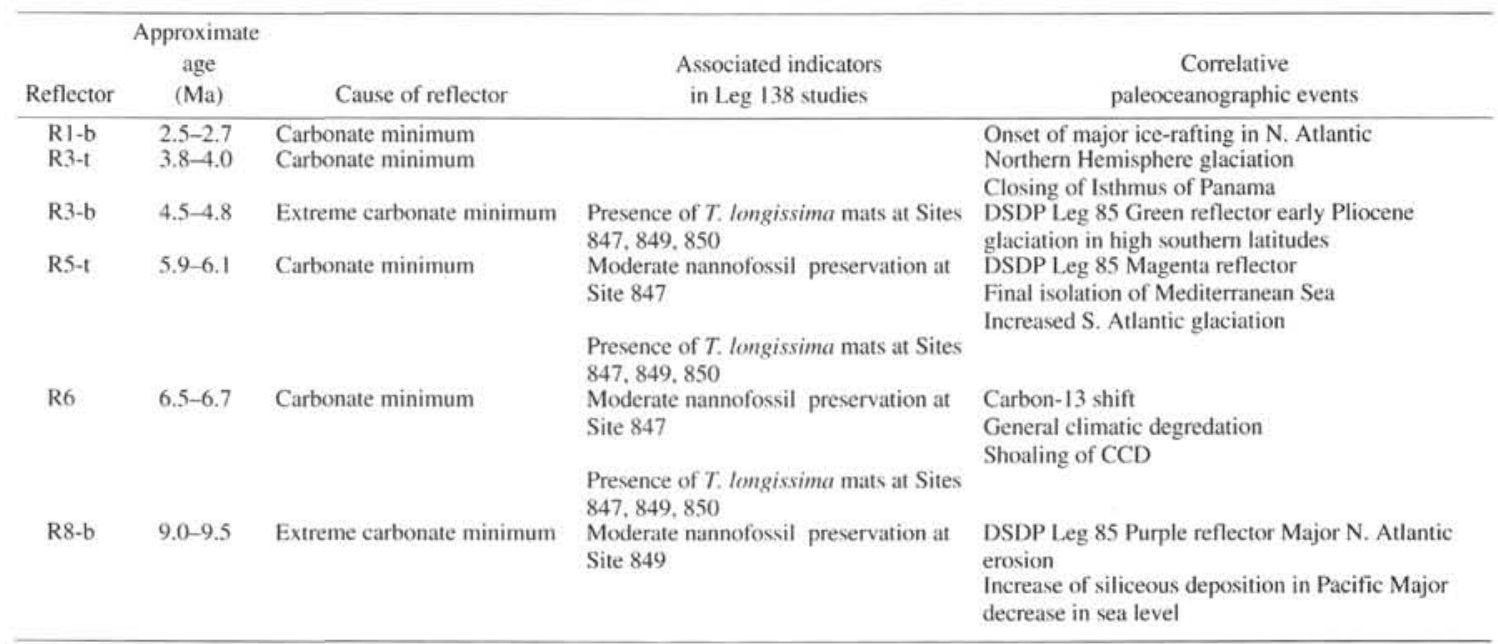

Table 2. Biostratigraphic zones for regional eastern equatorial Pacific reflectors.

\begin{tabular}{|c|c|c|c|c|}
\hline Leg & Reflector & Coccoliths & Radiolarians & Diatoms \\
\hline \multicolumn{5}{|l|}{138} \\
\hline & R1-b & $\mathrm{CN} 12 \mathrm{~b}-\mathrm{c}$ & P. prismatium & N. marina \\
\hline & $\mathrm{R} 3-\mathrm{t}$ & $\mathrm{CNIOC}$ & J. jenghisi & N. jouseae \\
\hline & R3-b & $\mathrm{CN} 10 \mathrm{c}$ & S. peregrina & N. jouseae \\
\hline & R5-I & $\mathrm{CN} 9 \mathrm{bB}$ & S. peregrina & T. convexa $\mathrm{B}$ \\
\hline & R5-b & CN9bA-B & S. peregrina & T. convexa $\mathrm{A}$ \\
\hline & R6 & CN9bA & $\begin{array}{l}\text { D. pentultima- } \\
\text { S. peregrina }\end{array}$ & N. miocenica $B$ \\
\hline & R8-1 & $\mathrm{CN} 8 \mathrm{a}-\mathrm{b}$ & D. antepentultima & T. yabei A \\
\hline & R8-b & CN7-CN8a & D. pettersoni & A. moronensis \\
\hline \multicolumn{5}{|l|}{85} \\
\hline & P-G & CNIOc? & $\begin{array}{l}\text { P. doliolum- } \\
\text { S. peregrina }\end{array}$ & N. jouseae \\
\hline & IM-M & $\mathrm{CN} 9 \mathrm{~b}$ & S. peregrina & T. convexa $\mathrm{B}$ \\
\hline & IM-B & $\mathrm{CN} 8 \mathrm{a}-\mathrm{b}$ & D. pentultima & $\begin{array}{l}\text { N. porteri B- } \\
\text { N. miocenica A }\end{array}$ \\
\hline & IM-P & $\mathrm{CN} 7$ & D. pettersoni & $\begin{array}{l}\text { A. moronensis- } \\
\text { T. yabei A }\end{array}$ \\
\hline
\end{tabular}

Note: Biostratigraphy is based on Mayer, Pisias, Janecek, et al. (1992).

creating a mechanism for reflector formation. Thus we may have synchronous reflectors that are all associated with low carbonate content -in the eastern equatorial Pacific this low carbonate content is a function of dilution while in the deeper central equatorial Pacific (and off the equator in the eastern Pacific), these low carbonate intervals are associated with enhanced dissolution. Future work will look at the seismic attributes of these reflectors to see if these transitions can be mapped.

\section{SUMMARY}

A series of eight reflectors or reflector packages were traced between two transects that connect five Leg 138 sites. By generating synthetic seismograms at each of these sites and by comparing these to the field records, the origin of these seismic reflectors was determined in terms of variations in physical properties and other core measurements. In particular, these reflectors usually were associated with sharp variations in density, which, in turn, are related to variations in carbonate content. In addition, by relating these reflectors to the presence of $T$. longissima mats and to nannofossil preservation 


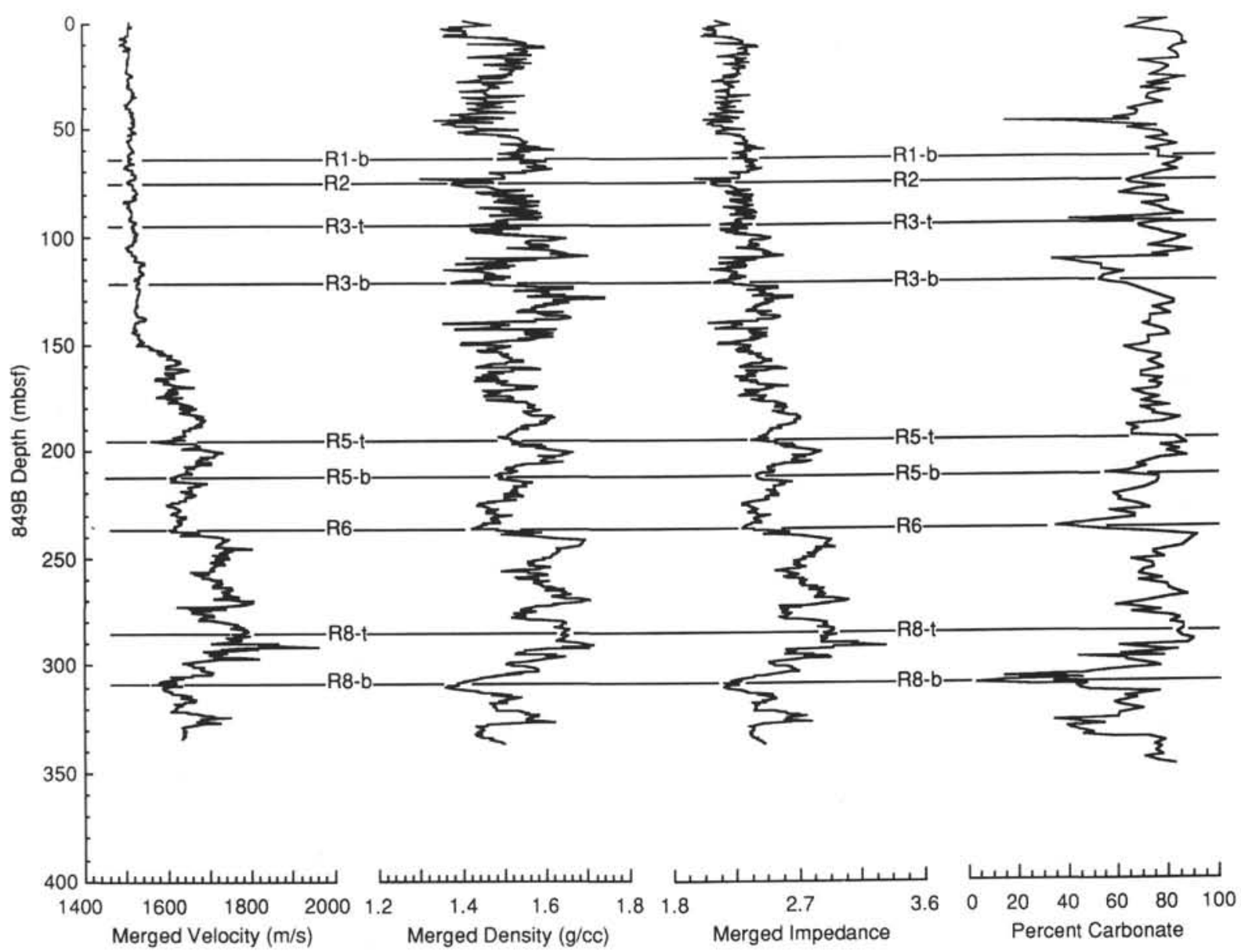

Figure 11. Plot of velocity, density, acoustic impedance, and carbonate content from ODP Site 849 with the depths of the reflectors traced in Figure 5 shown for comparison. Note that the reflectors correspond to sharp changes in carbonate content as well as physical properties.

indexes, we hoped to determine that the origin of these reflectors was the result of either productivity or dissolution events, respectively. Nannofossil preservation was generally good in the uppermost sediment recovered at these sites which suggests dissolution was not responsible for the presence of the region-wide reflectors found in this study. Many reflectors are related to the presence of $T$. longissima mats at some sites, and hence, these reflectors are related to productivity events. However, these reflectors were continuous at sites where mats of this diatom were not present, suggesting that these productivity related events are manifested in a different way at these sites than those where laminated intervals of $T$. longissima are present.

Interpreted seismic stratigraphic sections were compiled from the reflector horizon data for the two transects. Along the western transect, the section between reflectors R3 through R8 thins abruptly north of $1^{\circ} 40^{\prime}$ to $1^{\circ} 50^{\prime} \mathrm{N}$, suggesting that marks the northern limit of high equatorial productivity between 4 and $9.5 \mathrm{Ma}$, because the seafloor is reasonably constant in depth along this transect. Unfortunately, such statements about sharp productivity gradients cannot be made for the eastern transect, where sediment thinning corresponds to a deepening of the seafloor. However, no simple relationship between seafloor depth and sediment thickness exists, suggesting that productivity, and perhaps erosion, are important in the lateral variability in sediment thickness along this transect.

Finally, six reflectors were found to be associated with major paleoceanographic events; three of these reflectors correspond to those found by Mayer et al. $(1985,1986)$ in the central equatorial Pacific, suggesting that these correspond to Pacific-wide oceanographic events. This study provides the framework for further re- search on the relationship between seismic reflectors in the eastern and central equatorial Pacific Ocean.

\section{ACKNOWLEDGMENTS}

We would like to thank the officers, crew, and Leg 138 scientific staff of the JOIDES Resolution Leg 138 and those of the Thomas Washington Venture Leg 1 cruise. Many thanks must go to John Farrell, Sara Harris, Alan Kemp, and Kevin MacKillop for providing data required in this study. Thanks also go to two "anonymous" reviewers who made useful suggestions for improvement of the manuscript. S. Bloomer was supported with an NSERC post-graduate scholarship. Support for this work was supplied in part by NSERC, NSF, and the Office of Naval Research, Contract No. -NO0014-91-J-4166.

\section{REFERENCES}

Barron, J., Nigrini, C.A., Pujos, A., Saito, T., Theyer, F., Thomas, E., and Weinrich, N., 1985. Synthesis of biostratigraphy, central Equatorial Pacific, Deep Sea Drilling Project Leg 85: refinement of Oligocene to Quaternary biochronology. In Mayer, L., Theyer, F., Thomas, E., et al., Init. Repts. DSDP, 85: Washington (U.S. Govt. Printing Office), 905-934.

Berger, W.H., and Mayer, L.A., 1987. Cenozoic paleoceanography 1986: an introduction. Paleoceanography, 2:613-624.

\footnotetext{
"Abbreviations for names of organizations and publication titles in ODP reference lists follow the style given in Chemical Abstracts Service Source Index (published by American Chemical Society).
} 
Dunn, D.A., and Moore, T.C., 1981. Late Miocene-Pliocene (magnetic epoch 9-Gilbert magnetic epoch) calcium carbonate stratigraphy of the equatorial Pacific Ocean. Geol. Soc. Am. Bull., 92:408-451.

Hamilton, E.L., Bachman, R.T., Berger, W.H., Johnson, T.C., and Mayer, L.A., 1982. Acoustic and related properties of calcareous deep-sea sediments. $J$. Sediment. Petrol., 52:733-753.

Isern, A.R., 1991. Calcium carbonate and organic carbon accumulation in the central equatorial Pacific [M.S. thesis]. Univ, of Rhode Island.

Keigwin, L.D., 1979. Late Cenozoic stable isotope stratigraphy and paleoceanography of DSDP sites from the east equatorial and central North Pacific Ocean. Earth Planet. Sci. Lett., 45:361-382.

Kemp, A.E.S., and Baldauf, J.G., 1993. Vast Neogene laminated diatom mat deposits from the eastern equatorial Pacific Ocean. Nature, 362:141-144.

Lyle, M., Mayer, L., Pisias, N., Hagelberg, T., Dadey, K., Bloomer, S., and the Shipboard Scientific Party of Leg 138, 1992. Downhole logging as a paleoceanographic tool on Ocean Drilling Program Leg 138: interface between high-resolution stratigraphy and regional syntheses. Paleoceanography, 7:691-700.

Martinson, D.G., Menke, W., and Stoffa, P.L., 1982. An inverse approach to signal correlation. J. Geophys. Res., 87:4807-4818.

Mayer, L., Pisias, N., Janecek, T., et al., 1992. Proc. ODP, Init. Repts., 138 (Pts. 1 and 2): College Station, TX (Ocean Drilling Program).

Mayer, L.A., 1979. The origin of fine scale acoustic stratigraphy in deep-sea carbonates. J. Geophys. Res., 84:6177-6184.

Mayer, L.A., Courtney, R.C., and Moran, K., 1987. Ultrasonic measurements of marine sediment properties. Proc. Oceanogr., 87:1-139.

Mayer, L.A., Jansen, E., Backman, J., and Takayama, T., 1993. Climatic cyclicity at Site 806: the GRAPE record. In Berger, W.H., Kroenke, L.W., Mayer, L.A., et al., Proc. ODP, Sci. Results, 130: College Station, TX (Ocean Drilling Program), 623-639.

Mayer, L.A., Shipley, T.H., Theyer, F., Wilkens, R.H., and Winterer, E.L., 1985. Seismic modeling and paleoceanography at Deep Sea Drilling
Project Site 574. In Mayer, L.A., Theyer, F., Thomas, E., et al., Init. Repts. DSDP, 85: Washington, (U.S. Govt. Printing Office), 947-970.

Mayer, L.A., Shipley, T.H., and Winterer, E.L., 1986. Equatorial Pacific seismic reflectors as indicators of global oceanographic events. Science, 233:761-764.

Mosher, D.C., Mayer, L.A., Shipley, T.H., Winterer, E.L., Hagen, R.A., Marsters, J.C., Bassinot, F., Wilkens, R.H., and Lyle, M., 1993. Seismic stratigraphy of the Ontong Java Plateau. In Berger, W.H., Kroenke, L.W., Mayer, L.A., et al., Proc. ODP, Sci. Results, 130: College Station, TX (Ocean Drilling Program), 33-49.

Prell, W.L., 1985. Pliocene stable isotope and carbonate stratigraphy (Holes $572 \mathrm{C}$ and $573 \mathrm{~A})$ : paleoceanographic data bearing on the question of Pliocene glaciation. In Mayer, L., and Theyer, F., Thomas, E., et al., Init. Repts. DSDP, 85: Washington (U.S. Govt. Printing Office), 723-734.

Rio, D., Fornaciari, E., and Raffi, I., 1990. Late Oligocene through early Pleistocene calcareous nannofossils from western equatorial Indian Ocean (Leg 115). In Duncan, R.A., Backman, J., Peterson, L.C., et al., Proc. ODP, Sci. Results, 115: College Station, TX (Ocean Drilling Program), 175-235.

Shipboard Scientific Party, 1991. Site 803. In Kroenke, L.W., Berger, W. H., Janecek, T.R., et al., Proc. ODP, Init. Repts., 130: College Station, TX (Ocean Drilling Program), 101-176.

Vincent, E., 1981. Neogene carbonate stratigraphy of Hess Rise (central North Pacific) and paleoceanographic implications. In Thiede, J., Vallier, T.L., et al., Init. Repts. DSDP, 62: Washington (U.S. Govt. Printing Office), 571-606.

Wilson, W.D., 1960. Speed of sound in seawater as a function of temperature, pressure and salinity. J. Acoust. Soc. Am., 32:641-644.

Date of initial receipt: 19 February 1993

Date of acceptance: 19 October 1993

Ms 138SR-128

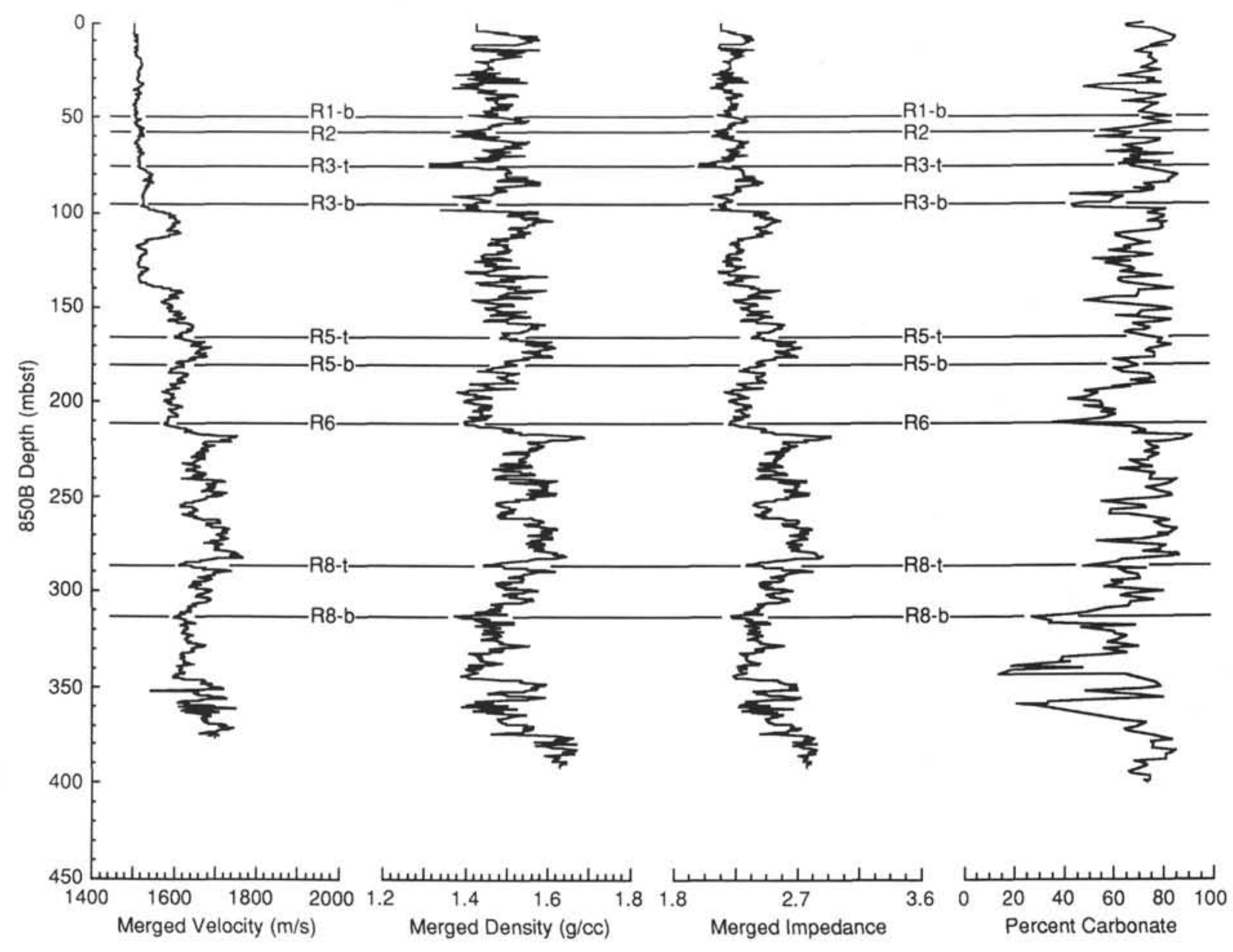

Figure 12. Plot of velocity, density, acoustic impedance, and carbonate content from ODP Site 850 , with the depths of the reflectors traced in Figure 6 shown for comparison. Note that the reflectors correspond to sharp changes in carbonate content as well as physical properties. 


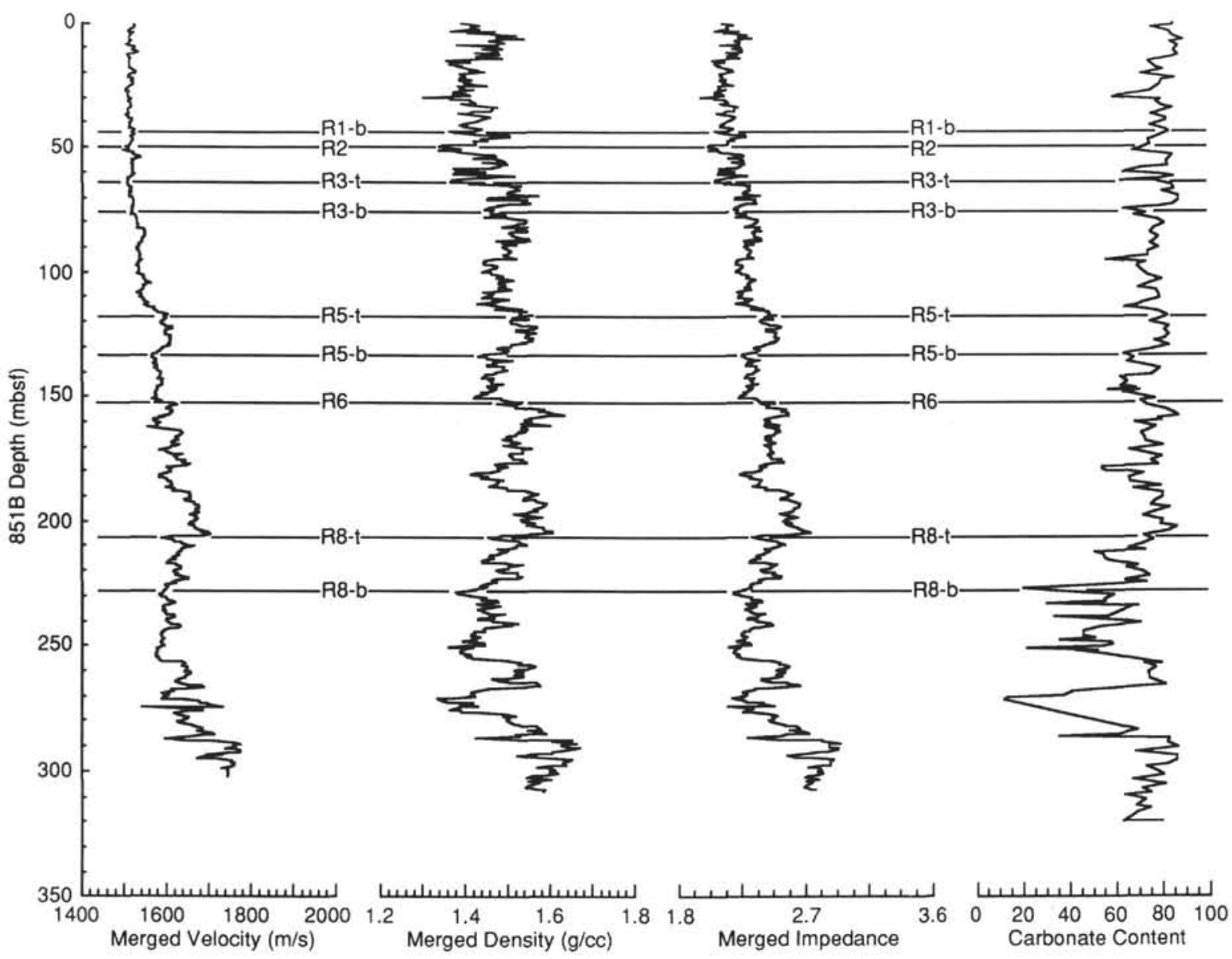

Figure 13. Plot of velocity, density, acoustic impedance, and carbonate content from ODP Site 851, with the depths of the reflectors traced in Figure 7 shown for comparison. Note that the reflectors correspond to sharp changes in carbonate content as well as physical properties. 


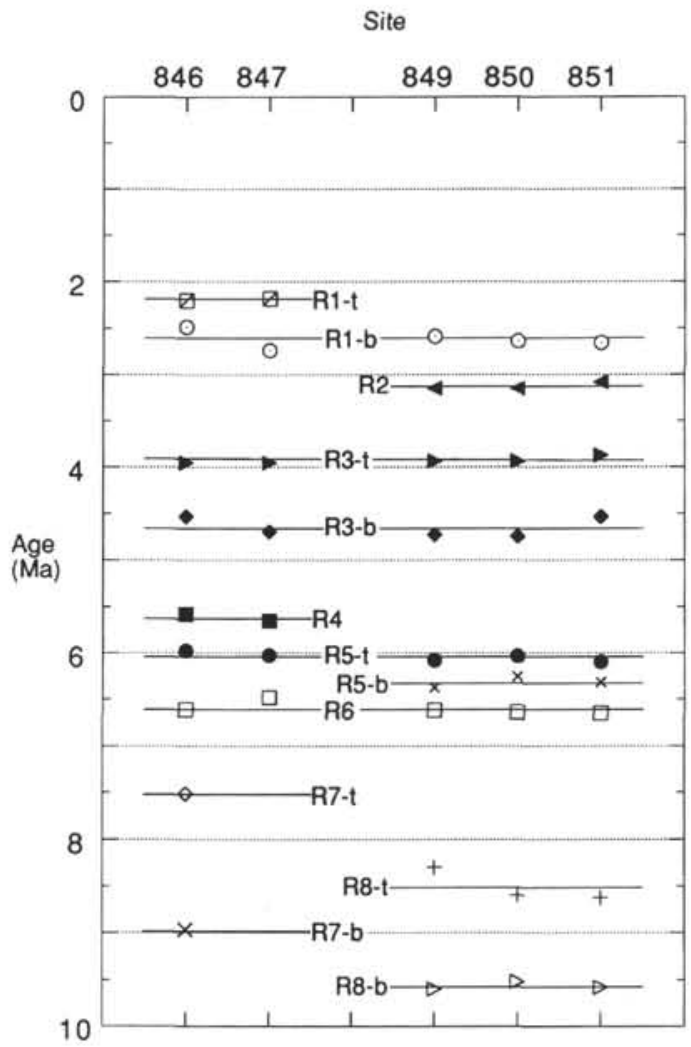

Figure 14. Plot of reflector age for the five sites in this study. The lines drawn through the age points for the various reflectors represent the average of the individual ages determined at each site. These lines demonstrate the amount of site to site variation in the age of the various reflectors.
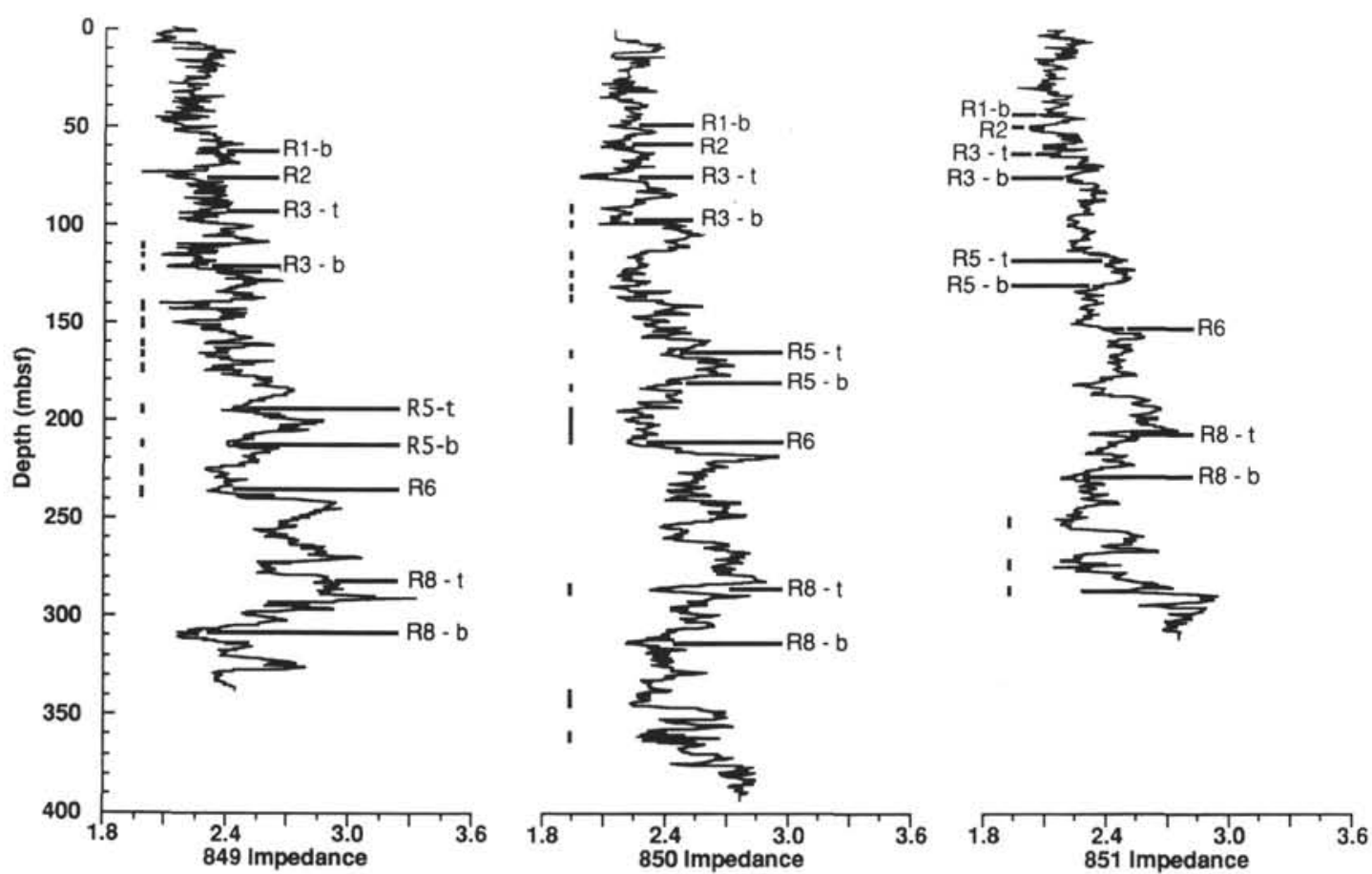

Figure 15. Plot of acoustic impedance, depths of reflectors, and intervals marked by the presence of $T$. longissima (shown by bars to the left of the acoustic impedance curves) from Sites 849 through 851 . Note that the labeled reflectors correspond well to similar variations in acoustic impedance between different holes. Reflector R3-b at Sites 849 and 850 corresponds to intervals with $T$. longissima, suggesting that this reflector is related to surface productivity. However, this reflector is traceable to Site 851 , where no $T$. longissima exists, so surface productivity may not be the only process responsible for this reflector. 

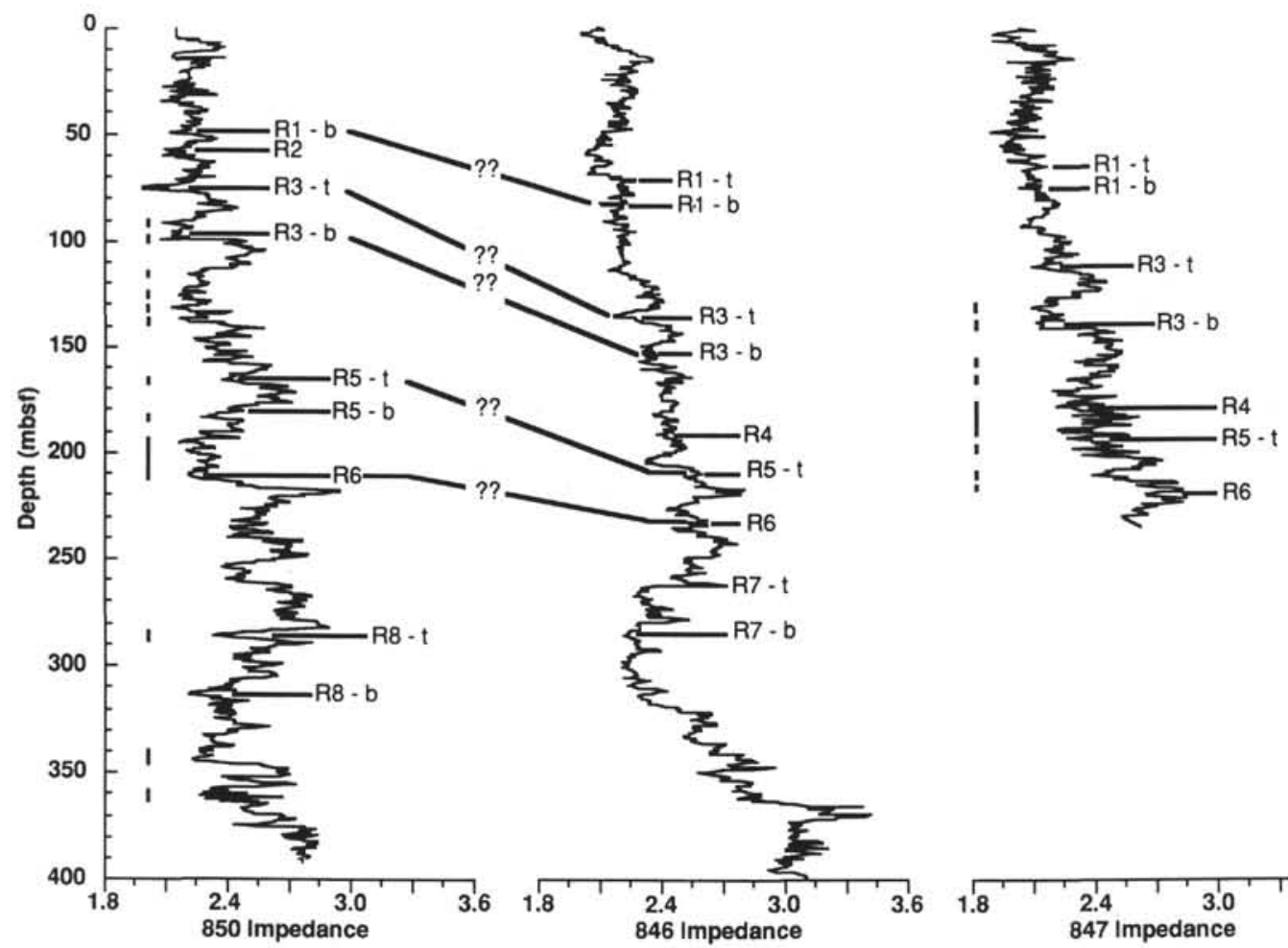

Figure 16. Plot of acoustic impedance, depths of reflectors, and intervals marked by the presence of $T$. longissima (shown by bars to the left of the acoustic impedance curves) from ODP Sites 846,847 , and 850 . Note that the labeled reflectors correspond well to similar variations in acoustic impedance between different holes. The lines connecting Sites 846 and 850 are labeled by question marks to indicate these connections have been inferred between the two transects on the basis of age and similarities in impedance variations.

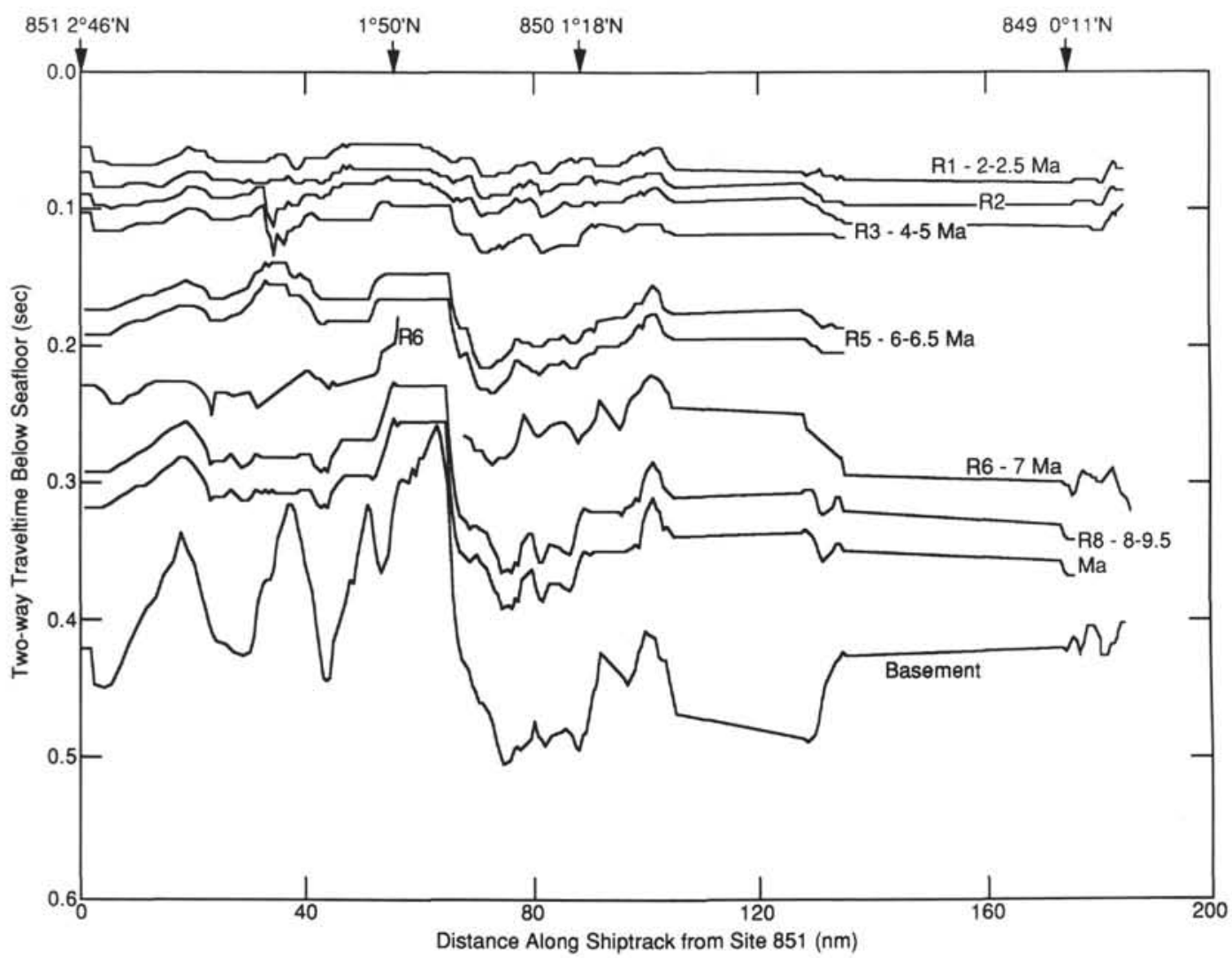

Figure 17. Interpreted seismic stratigraphy of the seismic reflection data extending from Site 849 to Site 851 along the trackline shown in Figure 1 . The sedimentary section between reflectors R3 and R8 thins abruptly between $1^{\circ} 40^{\prime} \mathrm{N}$ and $1^{\circ} 50^{\prime} \mathrm{N}$, suggesting that this marks the northern limit of the equatorial high-productivity belt at that time, as water depth is reasonably constant between Sites 850 and 851 . 


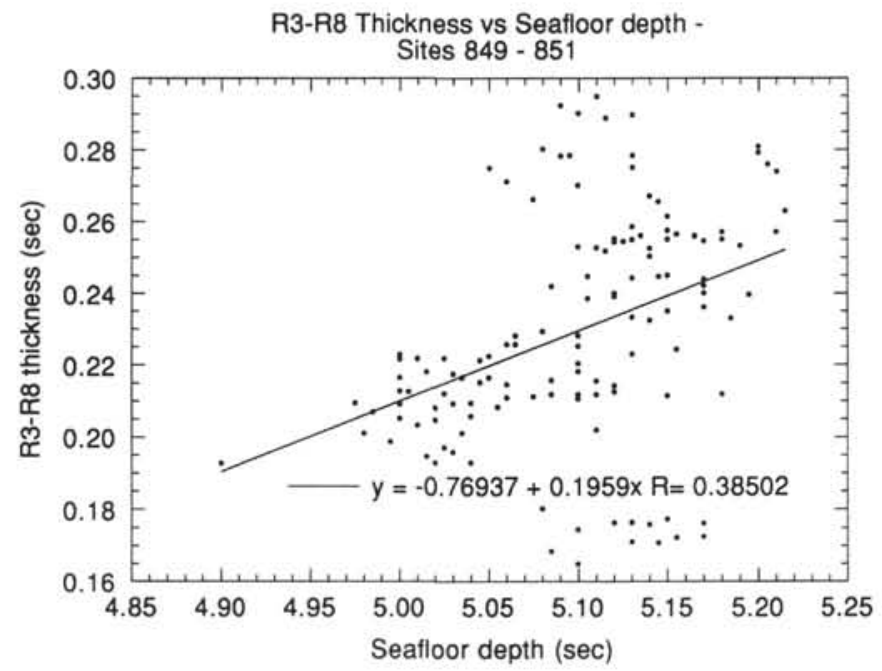

Figure 18. Plot of sediment thickness between reflectors R3 and R8 vs. water depth for the western transect of sites for the reflector horizons shown in Figure 15. Note the poor correlation between water depth and thickness, demonstrating that no simple relationship is suggestive of dissolution.

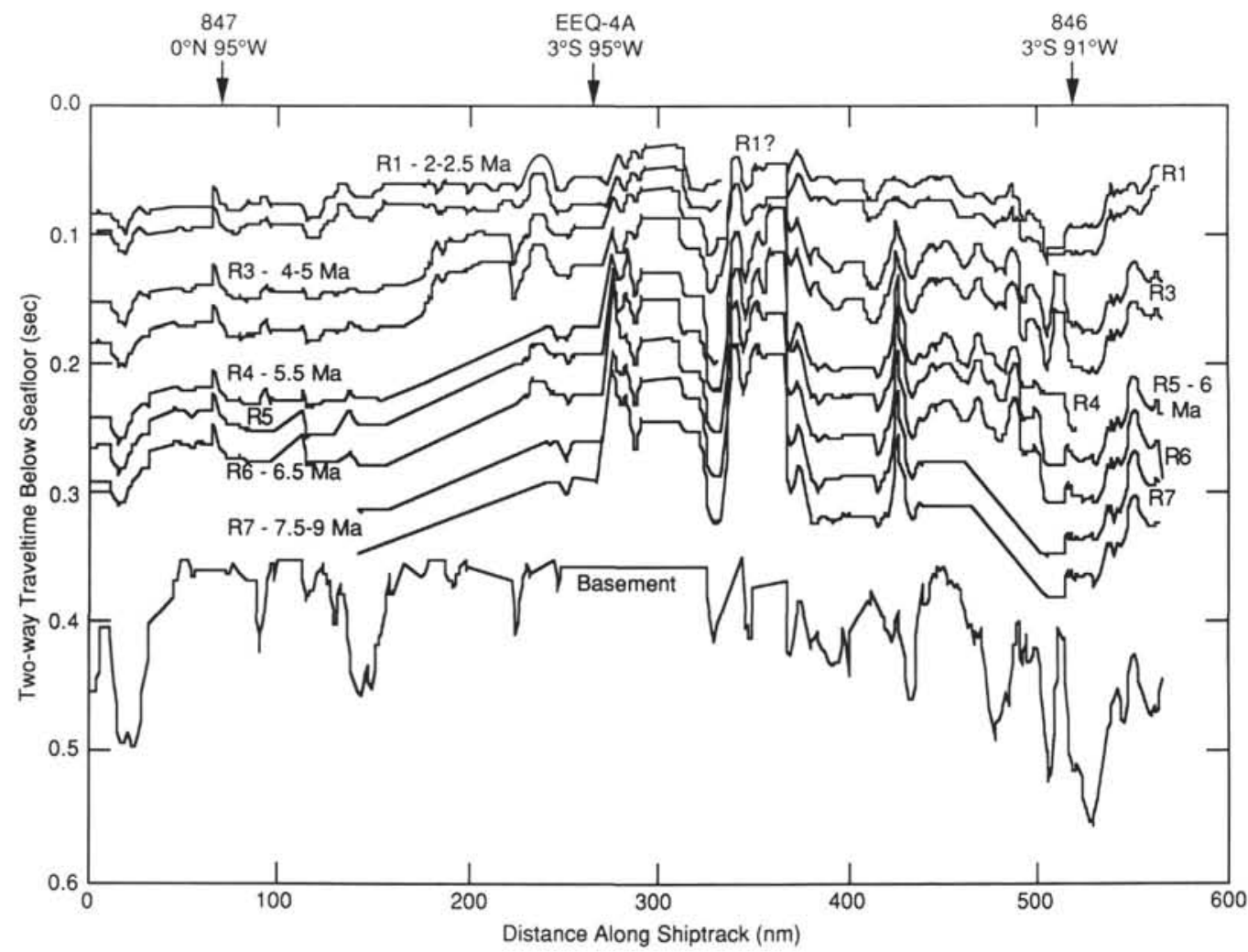

Figure 19. Interpreted seismic stratigraphy of the seismic reflection data for the eastern transect of sites along the trackline shown in Figure 1. Note that the sedimentary section between reflectors R1 and R6 thins abruptly between Site 847 and proposed Site EEQ-4A between 160 and $220 \mathrm{nmi}$ along the ship's track. Also note that the sedimentary section is reasonably constant in thickness between EEQ-4A and Site 846, but that the thickness of the section above reflector R1 thickens to the east and is greatly expanded near Site 846 . 
R1-R6 Thickness vs Seafloor Depth -

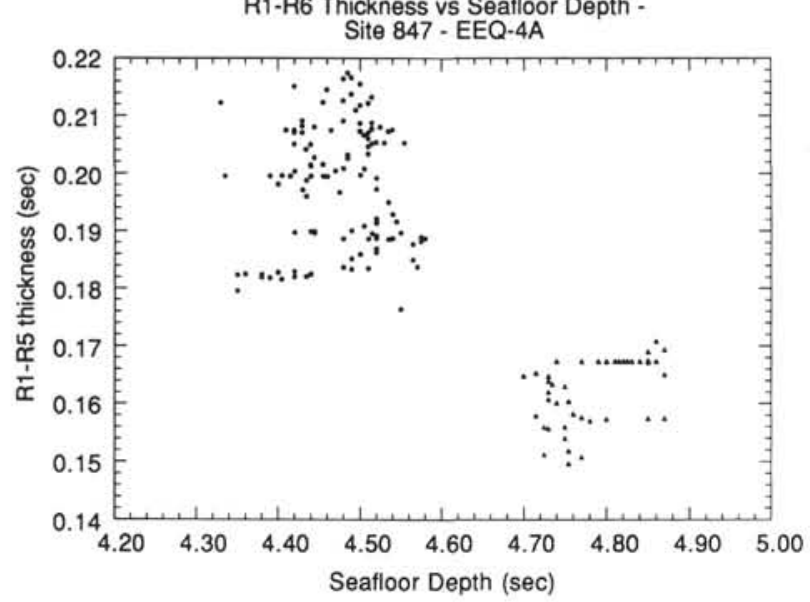

Figure 20. Plot of sediment thickness between reflectors R1 and R6 vs. water depth between Site 847 and proposed Site EEQ-4A for the reflector horizons shown in Figure 17. Note the poor correlation between water depth and thickness, demonstrating that no simple relationship is suggestive of dissolution. However, note that the points form two distinct groups, with all the shallower points (circles) north of the abrupt transition in thickness and the deeper points (triangles) south of this transition. Therefore, it is not possible to separate the cause of this southward thinning as either the result of dissolution with increasing water depth or as a sharp gradient in surface productivity.

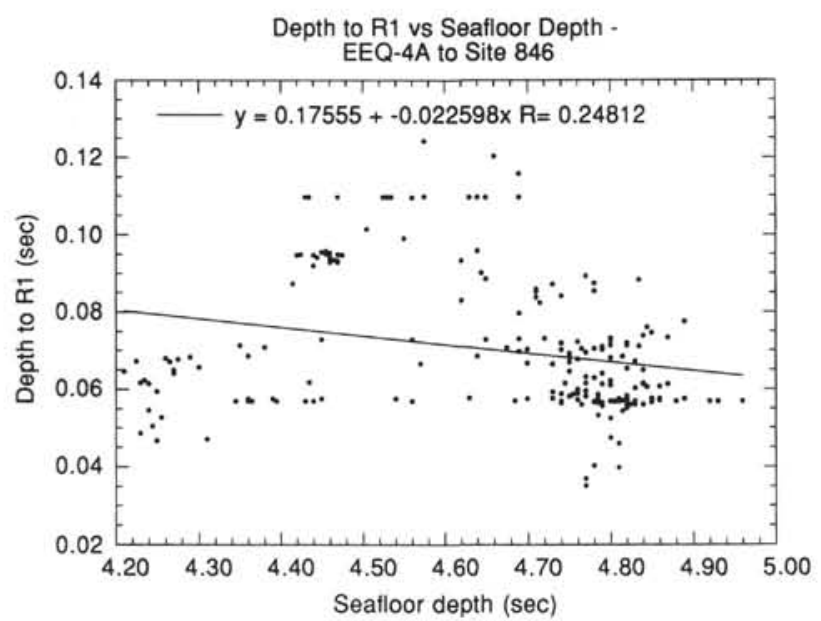

Figure 21. Plot of sediment thickness above reflector R1 vs. water depth between Site 846 and Site EEQ-4A for the reflector horizons shown in Figure 17. Note the poor correlation between water depth and thickness, demonstrating that no simple relationship is suggestive of dissolution alone to cause the thickening at Site 846. 